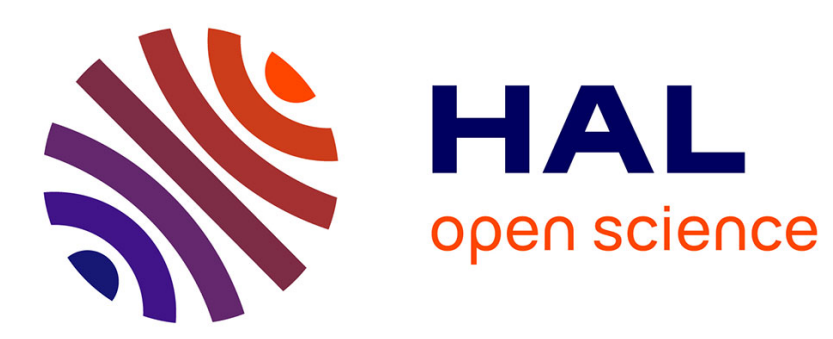

\title{
Density-functional theory investigation of hardness, stability, and electron-energy-loss spectra of carbon nitrides C11N4 stoichiometry
}

Maurizio Mattesini, Samir F. Matar

\section{- To cite this version:}

Maurizio Mattesini, Samir F. Matar. Density-functional theory investigation of hardness, stability, and electron-energy-loss spectra of carbon nitrides C11N4 stoichiometry. Physical Review B: Condensed Matter and Materials Physics (1998-2015), 2002, 65 (7), pp.075110. 10.1103/PhysRevB.65.075110 . hal-00705506

\section{HAL Id: hal-00705506 \\ https://hal.science/hal-00705506}

Submitted on 14 Sep 2020

HAL is a multi-disciplinary open access archive for the deposit and dissemination of scientific research documents, whether they are published or not. The documents may come from teaching and research institutions in France or abroad, or from public or private research centers.
L'archive ouverte pluridisciplinaire HAL, est destinée au dépôt et à la diffusion de documents scientifiques de niveau recherche, publiés ou non, émanant des établissements d'enseignement et de recherche français ou étrangers, des laboratoires publics ou privés. 


\title{
Density-functional theory investigation of hardness, stability, and electron-energy-loss spectra of carbon nitrides with $\mathrm{C}_{11} \mathrm{~N}_{4}$ stoichiometry
}

\author{
M. Mattesini* and S. F. Matar \\ Institut de Chimie de la Matière Condensée de Bordeaux, ICMCB-CNRS 87, Avenue du Dr. Albert Schweitzer, \\ F-33608 Pessac Cedex, France
}

(Received 20 February 2001; revised manuscript received 4 October 2001; published 31 January 2002)

\begin{abstract}
The characterization of carbon nitride films with stoichiometry $\mathrm{C}_{3} \mathrm{~N}_{4}$ is heavily restricted by the problem of getting pure crystalline samples with the right $\mathrm{C} / \mathrm{N}$ ratio. However, thin films with lower nitrogen concentration (5-25\%) have been found relatively easier to deposit, for example, with reactive magnetron sputtering. It is also in this range of nitrogen content that the recently discovered "graphiticlike $\rightarrow$ fullerenelike" phase transition has been suggested to take place. Therefore, in order to add more information to the above experimental evidence, it is important to use theoretical methods to obtain further characterization of carbon nitride models with a high $\mathrm{C} / \mathrm{N}$ ratio such as that of $\mathrm{C}_{11} \mathrm{~N}_{4}$. It is relevant to propose a cross checking on the role played by the nitrogen concentration in determining the stability, hardness, and electronic properties of $\mathrm{CN}_{x}$ compounds with different stoichiometries. For the sake of simplicity we have here compared the $\mathrm{C}_{3} \mathrm{~N}_{4}$ and $\mathrm{C}_{11} \mathrm{~N}_{4}$ systems, which are isoelectronic to each other. For this purpose two $\mathrm{C}_{11} \mathrm{~N}_{4}$ phases, namely, $\alpha$ and $\beta$, are presented and investigated with density-functional-theory methods within the local density approximation. These phases contain less than $\sim 30 \%$ of nitrogen than the well-known $\mathrm{C}_{3} \mathrm{~N}_{4}$ and are formally derived from the so-called pseudocubic $\mathrm{C}_{3} \mathrm{~N}_{4}$. Cohesive properties, heats of formation, bulk and elastic moduli have been calculated and a full detailed analysis of the density-of-states and energy-loss-near-edge-structure spectra is presented. We propose that the lowering of the nitrogen concentration does not prevent the finding of new ultrahard materials and indeed brings a significant increase in the cohesive energy of carbon nitrides. However, the computed enthalpies of formation have shown values that are positive and generally larger than the analog carbon-deficient phases.
\end{abstract}

DOI: 10.1103/PhysRevB.65.075110 PACS number(s): 71.15.Mb, 62.20.Qp, 71.20.-b, 79.20.Uv

\section{INTRODUCTION}

Networks made of covalently bonded carbon nitride are expected to show remarkable physical properties such as high hardness, wide band gap, and high thermal conductivity. They can be used as a protective coating on hard discs and recorder heads and are being tested for several other tribological applications. Other utilization areas can be found for example, in the flat-panel display industry. The possibility to synthesize nanotubelike ${ }^{1}$ and nanofiberlike ${ }^{2-4} \mathrm{CN}_{x}$ structures in a solid film may open the possibility of using such films for field-emission-electron sources. ${ }^{5-8}$ Carbon nitrides have also been tested for the development of ossointegrated joint arthroplasty. The major problem with these implants is the wear-debris generation, which provokes adverse tissue reactions. Carbon nitride has been identified as an interesting coating for use on human implants. ${ }^{9}$ Because of these great expectations they have rapidly become the focus of a great attention and nowadays they are widely investigated both experimentally and theoretically as potential candidates for new ultrahard materials. ${ }^{10}$ The starting interest on carbon nitrides dates back to Liu and Cohen's theoretical work ${ }^{11}$ of 1989 where the properties of the $\beta-\mathrm{C}_{3} \mathrm{~N}_{4}$ phase were proposed to be similar or even superior to those of diamond. From this finding many researchers were positively stimulated to find an adequate way to synthesize pure crystalline $\mathrm{C}_{3} \mathrm{~N}_{4}$ materials. The first attempt to make carbon nitride films was by Cuomo et al. in $1979,{ }^{12}$ who grew paracyanogenlike thin films with N/C ratios equal to 1 . Much more recently, a wide variety of techniques such as ion implantation, ${ }^{13}$ rf sputtering of carbon targets in a nitrogen atmosphere, ${ }^{14}$ plasma deposition of various hydrocarbons, ${ }^{15}$ nitrogen-ion implantation with simultaneous carbon-vapor deposition, ${ }^{16} \mathrm{dc}$ magnetron sputtering of a graphite target in a nitrogen ambient, ${ }^{17}$ shock-wave compression of carbon nitride precursor, $^{18}$ plasma-enhanced chemical vapor deposition, ${ }^{19}$ ion-assisted dynamic mixing, ${ }^{20}$ and laser ablation of a carbon target in a stream of atomic nitrogen ${ }^{21}$ have been investigated. From these attempts we know that many compositions of carbon nitrides exist and more than a few are stable to at least $800^{\circ} \mathrm{C}$. Therefore, many $\mathrm{CN}_{x}$ phases with different stoichiometries have similar stabilities and consequently mixed-phase deposits are quite often obtained. As a matter of fact, despite many efforts, the synthesis of carbon nitride films with stoichiometry $\mathrm{C}_{3} \mathrm{~N}_{4}(57.14 \%$ of nitrogen concentration) is still restricted to the production of amorphous samples with unclear crystallographic data. From the deposition of $\mathrm{CN}_{x}$ films, with $0 \leqslant x \leqslant 0.35$, by reactive magnetron sputtering in $\mathrm{Ar} / \mathrm{N}_{2}$ discharges we know that the maximum nitrogen concentration obtainable in the film is strongly dependent on the formation of stable molecules, such as $\mathrm{N}_{2}$ and $\mathrm{C}_{2} \mathrm{~N}_{2}$, that can with high probability desorb and leave the growth surface at even low substrate temperatures. ${ }^{22-24}$ Even though the nitrogen concentration in the film is not a very meaningful parameter, since amorphous films have been synthesized using different techniques with concentrations as high as $80 \%,,^{20,25}$ we do believe that it is important to make clear, at least at the theoretical level, how 
many different $\mathrm{CN}_{x}$ stoichiometries such as that of the $\mathrm{C}_{11} \mathrm{~N}_{4}$ could be in competition or even favored with respect to the formation of $\mathrm{C}_{3} \mathrm{~N}_{4}$ and what would be the changes in the mechanical and electronic properties if a pure crystalline $\mathrm{C}_{11} \mathrm{~N}_{4}$ material would be found.

The transition at $\sim 200^{\circ} \mathrm{C}$ from a graphitic phase to a "fullerenelike" phase, recently presented by N. Hellgren et al., ${ }^{22}$ could be imagined to take place from a graphitic form with a stoichiometry close to that of $\mathrm{C}_{11} \mathrm{~N}_{4}$. Indeed this transition is observed when the nitrogen concentration increases from $5 \%$ to $15 \%$ and the fullerenelike structure is found to be stable when the nitrogen amount is between $10 \%$ and $25 \%$. These concentrations are much closer to the $\mathrm{C}_{11} \mathrm{~N}_{4}$ stoichiometry than the well-known $\mathrm{C}_{3} \mathrm{~N}_{4}$. Moreover, the carbon-nitrogen ratio in $\mathrm{CN}_{x}$ films $(0.2 \leqslant x \leqslant 0.35)$ observed by $\mathrm{Sjöstrom} \mathrm{et} \mathrm{al.}{ }^{26}$ for buckled turbostatic microstructures formed at high temperatures is again close to the composition of $\mathrm{C}_{11} \mathrm{~N}_{4}$. Such carbon-nitrogen systems have been found to be both hard and elastic from nanoindentation experiments. $^{22,26}$

Hence, it becomes important to use theoretical methods and models to obtain further characterization and trends of the bonding configurations in $\mathrm{CN}_{x}$ structures. In the following sections we present a theoretical investigation of the stability and hardness for two different stoichiometries: $\mathrm{C}_{3} \mathrm{~N}_{4}$ and $\mathrm{C}_{11} \mathrm{~N}_{4}$. The analyzed systems are isoelectronic to each other and to diamond, although the nitrogen concentration on the second phase, $26.67 \%$, is much lower than the former one $(57.14 \%)$. We have here restricted our investigation to a novel class of compounds electronically analogous to diamond for which the same four averaged number of valence electrons per atom is kept. ${ }^{27-29}$ All the substances that satisfy this rule should possess similar properties to diamond, which is nowadays the hardest known material.

\section{METHODS AND COMPUTATIONAL DETAILS}

Calculations of the optimized geometries, relative stability, and elastic constants were performed $a b$ initio within the local-density approximation (LDA) to the density-functional theory $^{30}$ (DFT) using the Ceperley-Alder ${ }^{31}$ exchange correlation functional as parametrized by Perdew and Zunger ${ }^{32}$ and the ultrasoft pseudopotential (US-PP) method $^{33}$ (VASP $\left.\operatorname{code}^{34}\right)$. The calculations were performed by using an energy cutoff of $434.8 \mathrm{eV}$ for the plane-wave basis set and converged with respect to the $\mathbf{k}$-point integration. The tetrahedron method with Blöchl corrections ${ }^{35}$ was applied for both geometry relaxation and total-energy calculations. Brillouinzone integrals were approximated using the special k-point sampling of Monkhorst and Pack. ${ }^{36}$ Investigations of the density-of-states and electron-energy-loss-spectroscopy (EELS) spectra were carried out with the density-functionaltheory full-potential linearized augmented plane-wave (FPLAPW) program package WIEN97. ${ }^{37}$ The local-spin-density approximation according to Perdew and Wang was employed. ${ }^{38}$ The plane-wave cutoff was adjusted so that approximately 145 plane waves per atom were used for phases with $\mathrm{C}_{11} \mathrm{~N}_{4}$ stoichiometry. The differences in total energies are converged to below $0.001 \mathrm{eV}$ with respect to $\mathbf{k}$-point integration. For carbon and nitrogen atom types the same muffin-tin radius $\left(\mathrm{R}_{M T}=1.35 \AA\right)$ was used and maintained fixed for all the investigated structures. Only for the graphitic $\mathrm{C}_{11} \mathrm{~N}_{4}$ model a relative small $\mathrm{R}_{M T}$ value of $1.24 \AA$ was used. For diamond, graphite, and the $\mathrm{C}_{3} \mathrm{~N}_{4}$ phases, the values of $\mathbf{k}$ points and cutoff parameters are in accordance with our previous calculations. ${ }^{39}$

\section{A. General account to the hardness of various $\mathbf{C N}_{x}$ phases}

Hardness is commonly defined as the resistance of a material to deformations. This property strongly depends on many parameters like pressure, temperature, porosity, impurities, dislocations, and other defects and it is correlated to various other physical properties like ionicity, melting point, band gap, and cohesive energy. The bulk modulus, usually defined as $B$, measures the resistance to the volume change in solids and provides an estimation of the elastic response of the material to a hydrostatic pressure. Using the correlation between the bulk modulus and the hardness, many theoretical predictions on hard materials have been made during the last few decades. ${ }^{11,40-44}$ However, in 1977 Gerk $^{45}$ has already showed that for different materials such as fcc metals, $\mathrm{NaCl}$ structure, alkali halides, and other cubic solids, the magnitude of the shear modulus, defined as $G$, is better correlated to the experimental hardness than $B$. Much more recently Teter ${ }^{46}$ found the same general conclusions for a wide variety of materials, thus confirming the shear modulus as the best hardness predictor. The magnitude of $G$ describes the resistance of a material upon shape change and plays an important role in the elastic theory of dislocations. Hence, the hardness of a crystalline material should be closely correlated to how readily a large number of dislocations are generated and are able to move throughout the solid in response to the shear stresses. In our calculations, instead of the anisotropic shear modulus associated with the various slip systems of dislocation motions (see Ref. 47), we will consider only the average shear modulus. For sake of completeness we also present the values of $B$ to estimate the material resistance upon an isotropic compression. As shown below, $G$ can be expressed by means of elastic constants. The latter are usually measured by using ultrasonic techniques and Brillouin spectroscopy.

\section{Calculations of the elastic moduli}

In what follows we elucidate how the complete set of elastic constants can be deduced for a certain crystalline material. The elastic constants determine the response of the crystal to an externally applied strain (stiffness) and provide information about the bonding characteristics between adjacent atomic planes, anisotropic character of the bonding, and structural stability. The main problem in estimating elastic constants from first principles is not only the requirement of accurate methods for evaluating the total energy but also the heavy computations involved in their calculation. For instance, if the symmetry of the system is reduced, the number of independent moduli increases and hence a larger number of distortions is required to calculate the full set of elastic constants. The elastic behavior of a completely asymmetric 
TABLE I. Strains and elastic moduli for the orthorhombic phases.

\begin{tabular}{|c|c|c|}
\hline Strain & Parameters (unlisted $\delta_{i j}=0$ ) & Energy \\
\hline 1 & $\delta_{11}=\delta$ & $\Delta E=\frac{1}{2} V_{o} c_{11} \delta^{2}$ \\
\hline 2 & $\delta_{22}=\delta$ & $\Delta E=\frac{1}{2} V_{o} c_{22} \delta^{2}$ \\
\hline 3 & $\delta_{33}=\delta$ & $\Delta E=\frac{1}{2} V_{o} c_{33} \delta^{2}$ \\
\hline 4 & $\delta_{11}=\delta_{22}=\delta_{33}=\frac{1}{\left(1-\delta^{2}\right)^{1 / 3}}-1, \quad \delta_{23}=\delta_{32}=\frac{\delta}{\left(1-\delta^{2}\right)^{1 / 3}}-1$ & $\Delta E=2 V_{o} c_{44} \delta^{2}$ \\
\hline 5 & $\delta_{11}=\delta_{22}=\delta_{33}=\frac{1}{\left(1-\delta^{2}\right)^{1 / 3}}-1, \quad \delta_{13}=\delta_{31}=\frac{\delta}{\left(1-\delta^{2}\right)^{1 / 3}}-1$ & $\Delta E=2 V_{o} c_{55} \delta^{2}$ \\
\hline 6 & $\delta_{11}=\delta_{22}=\delta_{33}=\frac{1}{\left(1-\delta^{2}\right)^{1 / 3}}-1, \quad \delta_{12}=\delta_{21}=\frac{\delta}{\left(1-\delta^{2}\right)^{1 / 3}}-1$ & $\Delta E=2 V_{o} c_{66} \delta^{2}$ \\
\hline 7 & $\delta_{11}=\frac{1+\delta}{\left(1-\delta^{2}\right)^{1 / 3}}-1, \quad \delta_{22}=\frac{1-\delta}{\left(1-\delta^{2}\right)^{1 / 3}}-1, \quad \delta_{33}=\frac{1}{\left(1-\delta^{2}\right)^{1 / 3}}-1$ & $\Delta E=\frac{1}{2} V_{o}\left(c_{11}+c_{22}-2 c_{12}\right) \delta^{2}$ \\
\hline 8 & $\delta_{11}=\frac{1+\delta}{\left(1-\delta^{2}\right)^{1 / 3}}-1, \quad \delta_{22}=\frac{1}{\left(1-\delta^{2}\right)^{1 / 3}}-1, \quad \delta_{33}=\frac{1-\delta}{\left(1-\delta^{2}\right)^{1 / 3}}-1$ & $\Delta E=\frac{1}{2} V_{o}\left(c_{11}+c_{33}-2 c_{13}\right) \delta^{2}$ \\
\hline 9 & $\delta_{11}=\frac{1}{\left(1-\delta^{2}\right)^{1 / 3}}-1, \quad \delta_{22}=\frac{1+\delta}{\left(1+\delta^{2}\right)^{1 / 3}}-1, \quad \delta_{33}=\frac{1-\delta}{\left(1-\delta^{2}\right)^{1 / 3}}-1$ & $\Delta E=\frac{1}{2} V_{o}\left(c_{22}+c_{33}-2 c_{23}\right) \delta^{2}$ \\
\hline
\end{tabular}

material is specified by 21 independent elastic constants, while for an isotropic material, the number is two. In between these limits the necessary number is determined by the the crystal symmetry. ${ }^{48}$

Orthorhombic, tetragonal, and cubic systems. For an orthorhombic material there are nine independent elastic constants referred to as $c_{11}, c_{22}, c_{33}, c_{44}, c_{55}, c_{66}, c_{12}$, $c_{13}$, and $c_{23} .{ }^{49}$ They can be deduced by applying small strains to the equilibrium lattice and determining the resulting change in the total energy. The entire set of the elastic constants were determined by straining the lattice vectors according to the rule

$$
\widetilde{R}=R(1+\delta),
$$

where $\widetilde{R}$ and $R$ are the matrices that contain the components of the distorted and undistorted lattice vectors, 1 is the identity matrix, and $\delta$ the symmetric-distortion matrix

$$
\delta=\left(\begin{array}{lll}
\delta_{11} & \delta_{12} & \delta_{13} \\
\delta_{21} & \delta_{22} & \delta_{23} \\
\delta_{31} & \delta_{32} & \delta_{33}
\end{array}\right)
$$

The internal energy of a distorted crystal $E(V, \delta)$ can be Taylor expanded in powers of the components of $\delta$ with respect to the initial internal energy of the static crystal $E\left(V_{o}, 0\right)$ in the following way:

$$
E(V, \delta)=E\left(V_{o}, 0\right)+V_{o} \sum_{k=2}^{n} \sum_{i_{1} \cdots i_{k}} \frac{1}{k !} c_{i_{1} \cdots i_{k}} \delta_{i_{1}} \cdots \delta_{i_{k}} .
$$

$V$ and $V_{o}$ denote the volume of the strained and unstrained crystal and $c_{i_{1} \cdots i_{k}}$ denote the $k$ th order elastic con- stants of the unstrained crystal in the Voigt notation. In Eq. (3), the distortion components are defined according to $\delta_{k}$ $=\delta_{i j}$ for $k=1,2,3$ and $\delta_{k}=2 \delta_{i j}$ for $k=4,5$, and 6 . We evaluate the energy $E(V, \delta)$ by using the first-principles theory for different strains of the system. The Taylor expansion, limited to second-order, is here used to fit the numerical data. The elastic constants, $V_{o}$ and $E_{o}=E\left(V_{o}, 0\right)$ are the fitting parameters. The independent elastic constants for an orthorhombic material are found by considering nine different matrices $\delta$ to which correspond nine different expressions of the total energy (see Table I). The components of the distortion matrix [Eq. (2)] that do not appear in the table are set equal to zero. For each applied strain, the total energy of the system has been calculated for seven different small distortions $(\delta= \pm 0.02 n, n=0-3)$.

Relaxation of the internal degrees of freedom was carried out for all the applied deformations. The elastic constants were found by fitting the energies against the distortion parameter. A similar procedure has been used to deduce the six distinct, nonvanishing elastic constants ${ }^{50}\left(c_{11}, c_{12}, c_{13}, c_{33}\right.$, $c_{44}$ and $c_{66}$ ) for a tetragonal solid and the three independent moduli $^{51}\left(c_{11}, c_{12}\right.$, and $\left.c_{44}\right)$ for a cubic crystal system. A complete list of all the applied strains is shown in Tables II and III for the tetragonal and the cubic systems, respectively.

\section{Isotropic shear modulus}

The general formula of the isotropic shear modulus $G_{I s o}$ was first expressed by Reuss as long ago as in $1929 .{ }^{52}$ In Voigt's approximation the equation takes the following form:

$$
\begin{aligned}
G_{I s o}= & \frac{1}{15}\left[\left(c_{11}+c_{22}+c_{33}\right)-\left(c_{23}+c_{31}+c_{12}\right)\right. \\
& \left.+3\left(c_{44}+c_{55}+c_{66}\right)\right] .
\end{aligned}
$$


TABLE II. Strains and elastic moduli for the tetragonal phases.

\begin{tabular}{ccc}
\hline \hline Strain & Parameters (unlisted $\left.\delta_{i j}=0\right)$ & Energy \\
\hline 1 & $\delta_{11}=\delta_{22}=\delta$ & $\Delta E=V_{o}\left(c_{11}+c_{12}\right) \delta^{2}$ \\
2 & $\delta_{11}=\delta_{22}=\delta, \quad \delta_{33}=\frac{1}{\left(1+\delta^{2}\right)^{2}}-1$ & $\Delta E=V_{o}\left(c_{11}+c_{12}+2 c_{33}-4 c_{13}\right) \delta^{2}$ \\
3 & $\delta_{33}=\delta$ & $\Delta E=\frac{1}{2} V_{o} c_{33} \delta^{2}$ \\
4 & $\delta_{11}=\left[\frac{(1+\delta)}{(1-\delta)}\right]^{1 / 2}-1, \quad \delta_{22}=\frac{-\delta_{11}}{\left(1+\delta_{11}\right)}$ & $\Delta E=V_{o}\left(c_{11}-c_{12}\right) \delta^{2}$ \\
5 & $\delta_{31}=\delta_{32}=\delta_{13}=\delta_{23}=\frac{1}{2} \delta, \quad \delta_{33}=\delta^{2} / 4$ & $\Delta E=V_{o} c_{44} \delta^{2}$ \\
6 & $\delta_{12}=\delta_{21}=\frac{1}{2} \delta, \quad \delta_{11}=\delta_{22}=\left(1+\frac{\delta^{2}}{4}\right)^{1 / 2}-1$ & $\Delta E=\frac{1}{2} V_{o} c_{66} \delta^{2}$ \\
\hline \hline
\end{tabular}

Taking into account the proper symmetry relations, this modulus modifies as follows for an orthorhombic, tetragonal, and cubic system:

$$
\begin{gathered}
G_{o}=\frac{1}{15}\left(c_{11}+c_{22}+c_{33}-c_{12}-c_{13}-c_{23}\right)+\frac{1}{5}\left(c_{44}+c_{55}+c_{66}\right), \\
G_{t}=\frac{1}{15}\left(2 c_{11}+c_{33}-c_{12}-2 c_{13}+6 c_{44}+3 c_{66}\right), \\
G_{c}=\frac{1}{15}\left(3 c_{11}-3 c_{12}+9 c_{44}\right) .
\end{gathered}
$$

After having accomplished the calculation of the whole set of elastic constants, it is possible to estimate the shear moduli by simply applying the above linear relations. According to the finding of Gerk and Teter, the following trend is assumed: the larger the value of $G$, the harder is the material.

\section{Equation of state: The bulk modulus}

The following Birch equation of state: $:^{53}$

$$
\begin{aligned}
E(V)= & E\left(V_{o}\right)+\frac{9}{8} V_{o} B\left[\left(\frac{V_{o}}{V}\right)^{2 / 3}-1\right]^{2} \\
& +\frac{9}{16} B\left(B^{\prime}-4\right) V_{o}\left[\left(\frac{V_{o}}{V}\right)^{2 / 3}-1\right]^{3}
\end{aligned}
$$

TABLE III. Strains and elastic moduli for cubic systems. By calculating the tetragonal shear constant $C^{\prime}=\frac{1}{2}\left(c_{11}-c_{12}\right)$, and the bulk modulus $B=\frac{1}{3}\left(c_{11}+2 c_{12}\right)$, it is possible to extract $c_{11}$ and $c_{12}$.

\begin{tabular}{ccc}
\hline \hline Strain & Parameters (unlisted $\left.\delta_{i j}=0\right)$ & Energy \\
\hline 1 & $\delta_{11}=\delta_{22}=\delta, \quad \delta_{33}=\frac{1}{\left(1+\delta^{2}\right)}-1$ & $\Delta E=6 V_{o} C^{\prime} \delta^{2}$ \\
2 & $\delta_{12}=\delta_{21}=\delta, \quad \delta_{33}=\frac{\delta^{2}}{1-\delta^{2}}$ & $\Delta E=2 V_{o} c_{44} \delta^{2}$ \\
\hline
\end{tabular}

has been used to adjust the variation of the energy versus the unit-cell volume $V$ for an isotropic strain. The fitting parameters are $B, B^{\prime}, V_{o}$, and $E\left(V_{o}\right)$. The above equation represents a well-known and tested fitting form able to describe $P$, $V, T$ data for a wide class of solids. The main assumption is that no phase transition occurs during the compression of the material.

\section{THE ANALYZED CN NHASES $_{x}$ PHA}

In order to investigate the different properties of the $\mathrm{C}_{3} \mathrm{~N}_{4}$ and $\mathrm{C}_{11} \mathrm{~N}_{4}$ stoichiometries we present here a cross checking between two different kinds of $\mathrm{CN}_{x}$ phases: the stable twodimensional graphitic form and the hard three-dimensional pseudocubic system. First of all the graphitic phase has been chosen because it is representative of a stable layered $\mathrm{CN}_{x}$ network whereas it is pseudocubic for a hard threedimensional system. Second, since many three-dimensional $\mathrm{C}_{3} \mathrm{~N}_{4}$ phases have been proposed in the early works, ${ }^{44,54,55}$ as a starting point of our investigation we thought it worthwhile to focus attention only on certain phases for which the generation of the analogous $\mathrm{C}_{11} \mathrm{~N}_{4}$ stoichiometry can be easily figured out, for example, by simply doubling the length of one of the unit-cell vectors. The pseudocubic system results as a perfect example of a three-dimensional $\mathrm{C}_{3} \mathrm{~N}_{4}$ phase from which the corresponding $\mathrm{C}_{11} \mathrm{~N}_{4}$ can be readily generated without any drastic increase in the number of inequivalent atoms per unit cell. Details are given in the following sections.

\section{A. The graphitic and pseudocubic $\mathrm{C}_{3} \mathrm{~N}_{4}$}

The graphiticlike structure $\left(\mathrm{gr}-\mathrm{C}_{3} \mathrm{~N}_{4}\right)$ has been theoretically predicted to be the most stable $\mathrm{C}_{3} \mathrm{~N}_{4}$ form. ${ }^{39,44,54-56}$ For simplicity, the same intralayer geometry as in the hexagonal structure $\left(A B A\right.$ stacking) introduced by Teter and Hemley ${ }^{44}$ has been assumed in our graphiticlike model. Inside the layer each of the $\mathrm{C}$ atoms is threefold coordinated as is one of the four $\mathrm{N}$ atoms per cell, while the other three nitrogens show a two-fold coordination (see Fig. 1). The whole system was fully relaxed with the pseudopotential method assuming an $A A A$ packing sequence between the sheets. Such relaxation was required in order to adapt the intralayer geometry to the 
Front

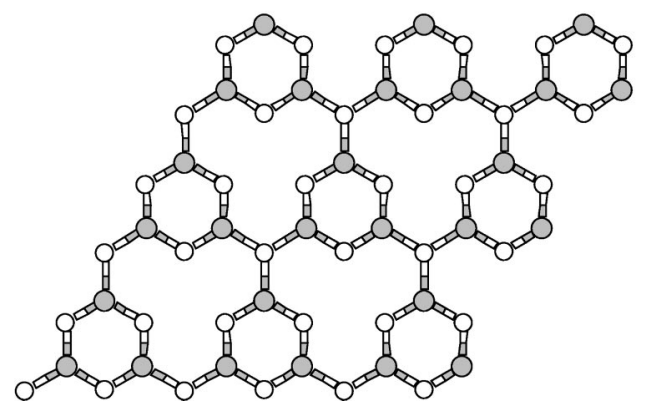

FIG. 1. One layer of gr- $\mathrm{C}_{3} \mathrm{~N}_{4}$. Carbon and nitrogen are depicted in gray and white respectively. This color scheme is kept throughout the paper.

new stacking order. Despite the fact that the $A A A$ packing is not the most energetically stable form, we have explicitly chosen to stack the layers directly on top of each other to enable an easier comparison of the results with the analogous graphiticlike $\mathrm{C}_{11} \mathrm{~N}_{4}$ form. ${ }^{57}$

The pseudocubic structure (psc- $\mathrm{C}_{3} \mathrm{~N}_{4}$ ) shown in Fig. 2 is usually called "defect zinc blende" and exhibits a $P \overline{4} 3 m$ symmetry and contains seven atoms per unit cell. ${ }^{44,55}$ This phase has been previously predicted by Liu and Wentzcovitch by substituting carbon and nitrogen in the pseudocubic $\alpha$-CdIn ${ }_{2} \mathrm{Se}_{4}{ }^{58}$ Since the psc- $\mathrm{C}_{3} \mathrm{~N}_{4}$ optimized in Ref. 55 has shown some residual forces in our pseudopotential code, we decided to fully relax again the system for better results. The new optimized geometry is shown in Table IV.

\section{B. The graphitic-, $\alpha$-, and $\beta-\mathrm{C}_{11} \mathrm{~N}_{4}$ phases}

The graphitic- $\mathrm{C}_{11} \mathrm{~N}_{4}\left(\right.$ gr- $\left.\mathrm{C}_{11} \mathrm{~N}_{4}\right)$ depicted in Fig. 3 has been theoretically introduced by $\mathrm{Snis}$ and co-workers in 1999. ${ }^{59,60}$ This phase is isoelectronic with diamond and $\mathrm{C}_{3} \mathrm{~N}_{4}$
Front

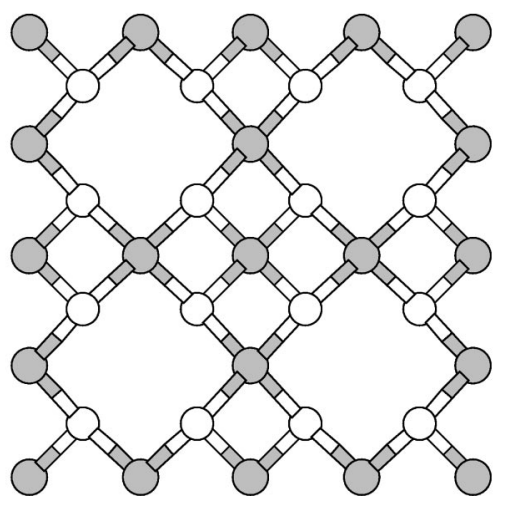

FIG. 2. Ball and stick model of the psc- $\mathrm{C}_{3} \mathrm{~N}_{4}$ structure. Figure shows the projection of the atoms along the [001] plane.

(Ref. 39) and has been suggested as a possible hard material. ${ }^{27}$ The configuration with layers in a stacking sequence $A A A$ has been fully geometry optimized with the same $a b$ initio pseudopotential plane-wave program. ${ }^{34}$ Details on the geometry and on the electronic properties can be found in the above-cited papers. It is certain that such a model system is not likely to show low compressibility due to the presence of weak interlayer bonding. Nonetheless, its major interests arise from the possibility to represent a lowenergy carbon-rich model structure.

The pseudocubic- $\mathrm{C}_{11} \mathrm{~N}_{4}$ configuration has been obtained from the analogous pseudocubic- $\mathrm{C}_{3} \mathrm{~N}_{4}$ phase by simply doubling the unit cell along the $a$ lattice vector. In order to reach the right stoichiometry one carbon has been added in the middle of the second cell, while the four nitrogen atoms, constituting the "nitrogen hole," have been substituted with four carbons. ${ }^{61}$ This phase is here called $\alpha-\mathrm{C}_{11} \mathrm{~N}_{4}$ (Fig. 4). Following the same procedure but performing a different atom substitution, another phase called $\beta-\mathrm{C}_{11} \mathrm{~N}_{4}$ can be ob-

TABLE IV. Optimized parameters for psc- $\mathrm{C}_{3} \mathrm{~N}_{4}$ and $\alpha-, \beta-\mathrm{C}_{11} \mathrm{~N}_{4}$. Cell constants are expressed in unit of angstroms while the angles $\alpha$, $\beta$, and $\gamma$ are in degrees.

\begin{tabular}{|c|c|c|c|}
\hline Property & psc- $\mathrm{C}_{3} \mathrm{~N}_{4}$ & $\beta-\mathrm{C}_{11} \mathrm{~N}_{4}$ & $\alpha-\mathrm{C}_{11} \mathrm{~N}_{4}$ \\
\hline Crystal system & Cubic & Orthorhombic & Tetragonal \\
\hline Space group & $P \overline{4} 3 m(215)$ & $P 222$ (16) & $P \overline{4} 2 m(111)$ \\
\hline Atoms/unit cell & 7 & 15 & 15 \\
\hline \multirow[t]{7}{*}{ Atom positions $(x, y, z)$} & $C_{1}(0.5000,0.5000,0.0000)$ & $C_{1}(0.5000,0.5000,0.2559)$ & $C_{1}(0.0000,0.5000,0.2575)$ \\
\hline & $N_{1}(0.2553,0.2553,0.2553)$ & $C_{2}(0.0000,0.5000,0.5000)$ & $C_{2}(0.0000,0.0000,0.0000)$ \\
\hline & & $C_{3}(0.0000,0.0000,0.2793)$ & $C_{3}(0.5000,0.5000,0.0000)$ \\
\hline & & $C_{4}(0.2315,0.2368,0.1392)$ & $C_{4}(0.2552,0.2552,0.1281)$ \\
\hline & & $C_{5}(0.0000,0.5000,0.0000)$ & $C_{5}(0.0000,0.0000,0.5000)$ \\
\hline & & $C_{6}(0.0000,0.0000,0.0000)$ & $N_{1}(0.2355,0.2355,0.6254)$ \\
\hline & & $N_{1}(0.7568,0.2680,0.3803)$ & \\
\hline \multirow[t]{3}{*}{ Cell constants } & $a=b=c=3.40865$ & $a=3.4454$ & $a=b=3.4944$ \\
\hline & & $b=3.5540$ & \\
\hline & & $c=7.2394$ & $c=6.9004$ \\
\hline$\alpha, \beta, \gamma$ & $90,90,90$ & $90,90,90$ & $90,90,90$ \\
\hline
\end{tabular}


Right

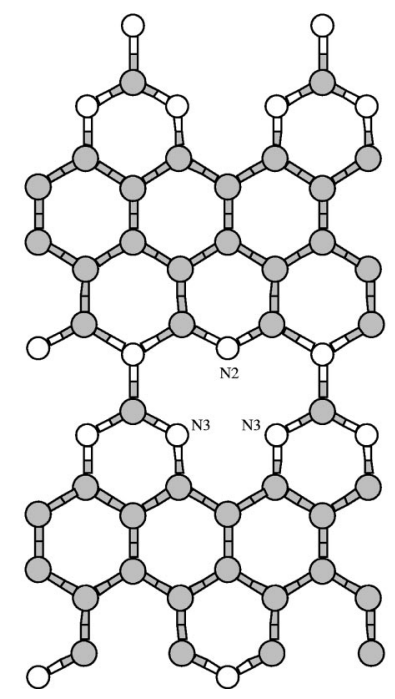

FIG. 3. One layer of gr- $\mathrm{C}_{11} \mathrm{~N}_{4}$.

tained (Fig. 5). The relaxation of the three-dimensional phases gives the final optimized geometries as shown in Table IV.

\section{PHASE STABILITY}

\section{A. Cohesive energies}

There is no doubt that one of the most important effects in determining the stability of carbon nitrides is the role played by the nonbonded N-N repulsions. These unfavorable electrostatic interactions have already been demonstrated to be relevant in accounting for the stability of some of the $\mathrm{C}_{3} \mathrm{~N}_{4}$ phases. ${ }^{62,63}$ In fact, an interesting tentative to remove such interactions was made in 1995 by T. Hughbanks and Y. Tian, ${ }^{62}$ who proposed the substitution of one $\mathrm{N}$ atom with one $\mathrm{C}$ to attenuate the critical $\mathrm{N}-\mathrm{N}$ lone-pair repulsion in the $\beta-\mathrm{C}_{3} \mathrm{~N}_{4}$ system. However, such a procedure imposes in most of the cases the use of new carbon-rich models (e.g., $\mathrm{C}_{4} \mathrm{~N}_{3}$ ) for which the departure from the isoelectronic systems becomes inevitable. In order to overcome this problem, and

Top

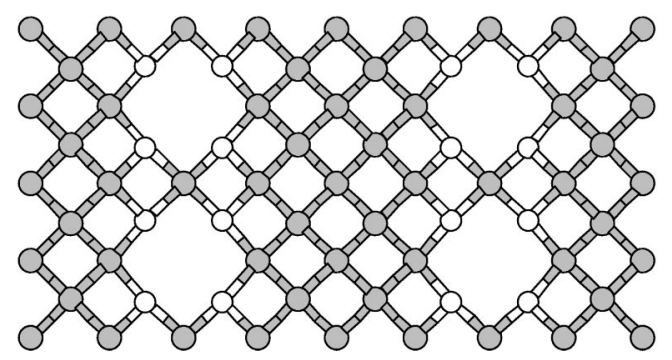

FIG. 4. Crystal structure of the tetragonal $\alpha-C_{11} N_{4}$. Projection along the [100] plane.
Top

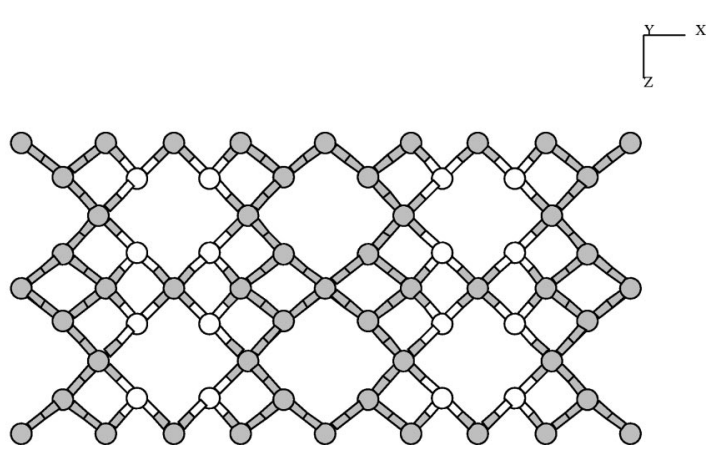

FIG. 5. Projection of the orthorhombic $\beta-C_{11} N_{4}$ crystal structure along the $[010]$ plane.

keep working on isoelectronic models, we have studied here $\mathrm{C}_{11} \mathrm{~N}_{4}$ systems on which the electrostatic contributions are kept similar to the analogous $\mathrm{C}_{3} \mathrm{~N}_{4}$ models. One may notice that a much more difficult and interesting task would be the use of isoelectronic model systems where the smothering of the N-N interactions is provided, for example, by avoiding lone pairs pointing directly one to each other. Unfortunately, despite many efforts we were not able to provide such a model $\mathrm{C}_{11} \mathrm{~N}_{4}$ phase. Nonetheless, focusing our attention only on the changing of the $\mathrm{C} / \mathrm{N}$ ratio, we found that the interactions between $\mathrm{sp}^{2}$-hybridized nitrogens (e.g., atoms of $\mathrm{N}_{3}$ and $\mathrm{N}_{2}$ of the 12-center carbon-nitrogen rings of Fig. 3) are not the only effects involved in accounting for the stability of carbon nitrides. As a matter of fact, the larger cohesive energy, i.e., the energy required to break apart a structure into isolated atoms, revealed by the $\mathrm{C}_{11} \mathrm{~N}_{4}$ stoichiometry (Table $\mathrm{V}$ ) is here addressed to the presence of a large number of carbon-carbon connections (see the ratio $R$ in the same Table $\mathrm{V})$, which have large bonding energy. According to the bondcounting rule, ${ }^{64-67}$ the more stable structure maximizes the number of highly energetic bonds. It is well known that bonds between elements from the second row of the periodic table in which one or both elements possess lone pairs are weaker than bonds in which neither of the constituents show lone pairs. The $\mathrm{C}-\mathrm{N}$ bonds $(260-320 \mathrm{~kJ} / \mathrm{mol})$ are in fact not as strong as $\mathrm{C}-\mathrm{C}$ bonds $(\sim 350 \mathrm{~kJ} / \mathrm{mol}) .{ }^{68,69}$ Therefore, it is mostly due to the presence of a large number of chains and/or rings, made of highly energetic $\mathrm{C}-\mathrm{C}$ bonds, that the $\mathrm{C}_{11} \mathrm{~N}_{4}$ stoichiometry possesses greater free-energy values with respect to the $\mathrm{C}_{3} \mathrm{~N}_{4}$ composition (see Fig. 6 and Table $\mathrm{V})$. More precisely, its graphitic form is energetically well below, $0.98 \mathrm{eV} /$ atom with the US-PP/LDA method, the corresponding $\mathrm{gr}-\mathrm{C}_{3} \mathrm{~N}_{4}$ as is the three-dimensional $\alpha$ phase

TABLE V. Cohesive energy (in eV/atom) with respect to the spin-polarized atoms and the ratio $R$ (number of C-C bonds over the number of $\mathrm{C}-\mathrm{N}$ bonds per unit cell) for various $\mathrm{C}_{3} \mathrm{~N}_{4}$ and $\mathrm{C}_{11} \mathrm{~N}_{4}$ model systems.

\begin{tabular}{cccccc}
\hline US-PP/LDA & $\mathrm{gr}^{-\mathrm{C}_{3} \mathrm{~N}_{4}}$ & ${\mathrm{psc}-\mathrm{C}_{3} \mathrm{~N}_{4}}$ & $\mathrm{gr}^{-\mathrm{C}_{11} \mathrm{~N}_{4}}$ & $\alpha-\mathrm{C}_{11} \mathrm{~N}_{4}$ & $\beta-\mathrm{C}_{11} \mathrm{~N}_{4}$ \\
\hline$E_{\text {coh. }}$ & -7.081 & -6.935 & -8.063 & -8.035 & -7.070 \\
$R$ & $0: 14$ & $0: 12$ & $26: 12$ & $16: 12$ & $16: 12$ \\
\hline
\end{tabular}




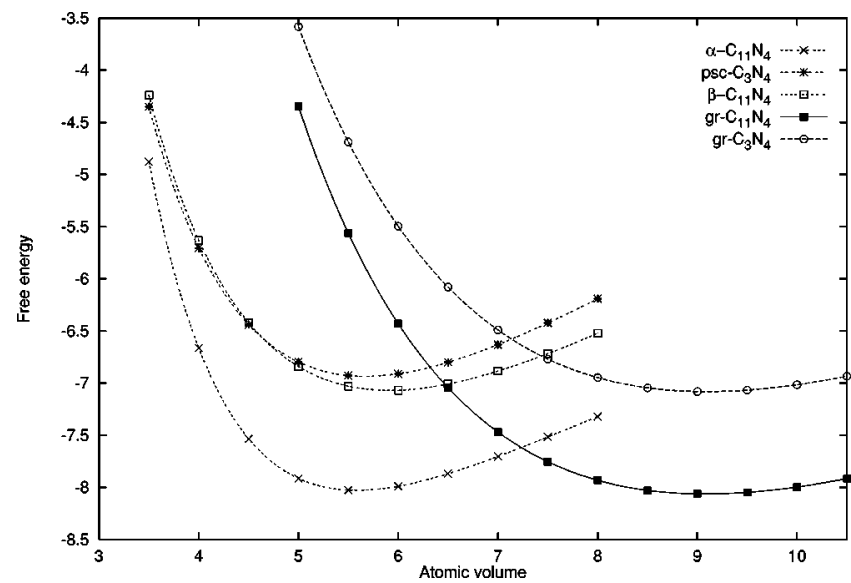

FIG. 6. Free energies (eV/atom) versus atomic volumes ( $\AA^{3}$ /atom) for various $\mathrm{C}_{3} \mathrm{~N}_{4}$ and $\mathrm{C}_{11} \mathrm{~N}_{4}$ phases (US-PP).

(1.10 eV/atom). In particular, the layered $\mathrm{C}_{11} \mathrm{~N}_{4}$ phase is more stable than the comparable $\mathrm{C}_{3} \mathrm{~N}_{4}$ model because of the presence of an extended graphiticlike matrix around the carbon-nitrogen ring in the direction of the $b$ axis (Fig. 3). The introduced carbon system with $13 \mathrm{C}-\mathrm{C}$ bonds per layer is here responsible of an evident lowering of the energy of the system. Such a model phase results also as the most stable $\mathrm{C}_{11} \mathrm{~N}_{4}$ form not only because of the highest fraction of $\mathrm{C}-\mathrm{C} / \mathrm{C}-\mathrm{N}$ bonds but also because of the possibility to delocalize the nitrogen's lone pair (atoms $\mathrm{N}_{2}$ and $\mathrm{N}_{3}$ ) into the graphiticlike matrix. Similarly, the same delocalization effect is present in $g r-\mathrm{C}_{3} \mathrm{~N}_{4}$, where lone pairs can be dispersed into the $\pi$-electron circulation of the $\mathrm{C}_{3} \mathrm{~N}_{3}$ rings. It is because of this peculiar characteristic that layered phases represent, in both stoichiometries, the low-energy structure model. ${ }^{70}$ In three-dimensional phases the above possibility is limited by the presence of a uniform framework with $s p^{3}$ bonds. However, the introduced diamondlike matrix with 16 strong C-C bonds per unit cell (Table V) limits in the $\alpha$ phase (Fig. 4) the propagation of the neighboring carbon-nitrogen holes to the $b$ axis. Compared to the psc- $\mathrm{C}_{3} \mathrm{~N}_{4}$ analog (Fig. 2), where each of the carbon-nitrogen rings is surrounded by four others (network of pure $\mathrm{C}-\mathrm{N}$ bonds), we have here reached a mixed C-C/C-N system using the same averaged number of valence electrons. It is thus on the possibility to fit and weight the carbon-nitrogen ring into a more stable threedimensional carbon network that the $\alpha-\mathrm{C}_{11} \mathrm{~N}_{4}$ is energetically favorable over psc- $\mathrm{C}_{3} \mathrm{~N}_{4}$. However, in spite of this general finding a very low stability has been predicted for the $\beta$ phase, where the presence of a "carbon hole" drastically destabilizes the three-dimensional $\mathrm{C}_{11} \mathrm{~N}_{4}$ arrangement. More precisely, the poor stability can be here attributed to the presence of carbon atoms (i.e., $\mathrm{C}_{4}, \mathrm{C}_{5}$, and $\mathrm{C}_{6}$ ) with dangling bonds in the carbon cavity. Based on these considerations, in the following sections, we will mostly focus our attention on the $\alpha$ model.

\section{B. Phase transitions}

Only a modest pressure is needed to overcome the energy barrier separating the graphitic and $\alpha-\mathrm{C}_{11} \mathrm{~N}_{4}$ phase and to induce a transition between them. Estimation of this pressure from the slope at the common energy/volume intersection gives a hydrostatic transition pressure necessary for the transfer less than $\sim 2 \mathrm{GPa}(1.7 \mathrm{GPa})$. Again from the slope at the common energy intersection we calculate that a pressure of about $82 \mathrm{GPa}$ is needed to go from the graphitic- to the $\beta-\mathrm{C}_{11} \mathrm{~N}_{4}$ phase.

\section{Thermodynamic stability}

When considering the possibility to synthesize carbon nitrides, one has also to account for their thermodynamic stability with respect to the starting materials. In this section, the phase stability has been theoretically estimated for each of the studied $\mathrm{CN}_{x}$ model systems by computing the magnitude of the molar enthalpy change of formation at $0 \mathrm{~K}$ $\left(\Delta H_{f, 0}\right)$. The following reactions energy have been considered:

$$
\begin{aligned}
& 3 \mathrm{C}_{(s)}+2 \mathrm{~N}_{2(g)} \rightarrow \mathrm{C}_{3} \mathrm{~N}_{4(s)}, \\
& 11 \mathrm{C}_{(s)}+2 \mathrm{~N}_{2(g)} \rightarrow \mathrm{C}_{11} \mathrm{~N}_{4(s)} .
\end{aligned}
$$

For simplicity we have assumed the reaction between diamond, which is only slightly less stable than graphite $(\sim 0.001 \mathrm{eV} /$ atom within the US-PP/LDA calculational scheme), and nitrogen to form carbon nitrides.

In order to have a quantitative insight into the stability of carbon nitrides with respect to decomposition of the starting elements, accurate values of their cohesive energies $\mathrm{E}_{c o h}$ are needed. Then, by calculating the theoretical values for the energy required to dissociate the nitrogen molecule and the cohesive energy of diamond, the enthalpy change for the reactions (10) and (9) can easily be evaluated. It is well known that the DFT/LDA approach normally tends to overestimate the cohesive energies for structures made of elements of the second row of the periodic table such as carbon and nitrogen. ${ }^{71,72}$ The computed cohesive energy of diamond is in fact significantly overestimated (see Table VI and Ref. 84 for further details) with respect to the experimental value. $^{73}$ This general tendency of the LDA to overvalue the strength of the $\mathrm{C}-\mathrm{C}$ and $\mathrm{C}-\mathrm{N}$ bonds can, in principle, be reduced by using the generalized gradient corrections. ${ }^{38}$ However, since our goal is here to provide only a general thermodynamic tendency for the two stoichiometries, we have decided to limit our investigation only to the LDA calculations. Furthermore, in order to obtain adequate cancellation of the typical overbinding energies, the cohesive properties of $\mathrm{N}_{2(g)}$ and diamond listed in Table VI were also calculated at the same LDA level as the right-hand side of the formation reactions. All the calculated cohesive energies have been obtained by taking the difference between the total energy of the solids and the ground-state energies of the spin-polarized atoms. No correction for zero-point motion has been made. The computed US-PP values are shown in Tables V and VI for the studied $\mathrm{CN}_{x}$ model phases and references, respectively.

It should also be considered that the $a b$ initio calculation of the cohesive energies is not the only method able to predict the enthalpies of carbon nitrides. An elegant investiga- 
TABLE VI. Cohesive energies (eV/atom) for the starting materials with respect to the spin-polarized atoms: diamond (carbon-rich regime) and $\mathrm{N}_{2}$ (nitrogen-rich regime). For the calculations of the nitrogen dimer, a simple cubic cell $(a=7 \AA)$ has been employed with atoms displaced along the diagonal direction. In this special case the calculations were performed along the $\Gamma$ point.

\begin{tabular}{lcc}
\hline \hline & Diamond & $\mathrm{N}_{2}$ \\
\hline US-PP & -9.003 & -11.853 \\
& $-9.03^{\mathrm{a}}$ & $-11.34^{\mathrm{b}}$ \\
& $-8.87^{\mathrm{c}}$ & $-11.60^{\mathrm{d}}$ \\
& $-8.50^{\mathrm{e}}$ & - \\
$-8.43^{\mathrm{f}}$ & - \\
$-7.58^{\mathrm{g}}$ & - \\
& $-7.37^{\mathrm{f}, \mathrm{h}}$ & $-9.91^{\mathrm{i}}$ \\
\hline \hline
\end{tabular}

${ }^{\mathrm{a}}$ Reference 84 .

${ }^{\mathrm{b}}$ Reference 88 .

${ }^{\mathrm{c}}$ Reference 89.

${ }^{\mathrm{d}}$ Reference 82 .

${ }^{\mathrm{e}}$ Reference 86.

${ }^{\mathrm{f}}$ Reference 83 .

${ }^{\mathrm{g}}$ Reference 85 .

${ }^{\mathrm{h}}$ Reference 87.

${ }^{\mathrm{i}}$ References 80 and 81 .

tion has in fact already been given in 1997 by Badding. ${ }^{63} \mathrm{He}$ proposed a simple chemical approach to the thermodynamic stability of $\mathrm{C}_{3} \mathrm{~N}_{4}$ compounds starting from the use of the bond enthalpies derived from pure molecular systems. The basic idea behind this approach is that, covalently bonded compounds such as diamond and carbon nitrides can be thought of as "giant molecules," so that simple bondenthalpy techniques can be employed to estimate their stability. Our results will be confronted in the next paragraph with the earlier values obtained with the aforementioned chemical method.

a. $C_{3} N_{4}$. In Eq. (9) it is noteworthy that both diamond and molecular nitrogen possess strong bonds (C-C $\sim 350 \mathrm{~kJ} / \mathrm{mol}$ and $\mathrm{N}-\mathrm{N} \sim 956 \mathrm{~kJ} / \mathrm{mol}$ ) while the reaction product $\left(\mathrm{C}_{3} \mathrm{~N}_{4}\right)$ contains only weaker $\mathrm{C}-\mathrm{N}$ bonds (260-320 $\mathrm{kJ} / \mathrm{mol}$ ). It is thus very probable that carbon nitrides will likely behave as thermodynamically unstable substances under normal atmospheric pressures. Nevertheless, if a synthetic process can deposit $\mathrm{C}_{3} \mathrm{~N}_{4}$ materials, a rather large activation energy would be needed to break apart the various $\mathrm{C}-\mathrm{N}$ bonds constituting the system. ${ }^{63}$ As a consequence, carbon nitrides could result metastable systems at ambient conditions, thus opening the possibility of their use as novel hard materials.

Employing the calculated US-PP cohesive energies of Tables V and VI we obtain the values of the molar enthalpy changes of formation as listed in Table VII. The estimated $\Delta H_{f, 0}$ for Eq. (9) are all largely positive, though their magnitudes are fairly lower than the enthalpies of formation derived from Badding's method (i.e., 588-816 $\mathrm{kJ} / \mathrm{mol}$ for the three-dimensional $\beta-\mathrm{C}_{3} \mathrm{~N}_{4}$ system). In particular, for the layered gr- $\mathrm{C}_{3} \mathrm{~N}_{4}$ a positive enthalpy of formation of $110.8 \mathrm{~kJ} /$ mol has been computed, which points to a thermodynami-
TABLE VII. Calculated enthaplies of formation $\left(\Delta H_{f, 0}\right.$ in $\mathrm{kJ} /$ mol) for different $\mathrm{C}_{3} \mathrm{~N}_{4}$ and $\mathrm{C}_{11} \mathrm{~N}_{4}$ compounds.

\begin{tabular}{|c|c|c|c|c|}
\hline US-PP/LDA & gr- $\mathrm{C}_{3} \mathrm{~N}_{4}$ & $\mathrm{gr}-\mathrm{C}_{11} \mathrm{~N}_{4}$ & psc- $\mathrm{C}_{3} \mathrm{~N}_{4}$ & $\alpha-\mathrm{C}_{11} \mathrm{~N}_{4}$ \\
\hline$\Delta H_{f, 0}$ & 110.8 & 173.1 & 209.4 & 213.7 \\
\hline
\end{tabular}

cally unfavorable reaction to form the compound. In the same way we have calculated a larger and positive $\Delta H_{f, 0}$ of $209.4 \mathrm{~kJ} / \mathrm{mol}$ for the $\mathrm{psc}-\mathrm{C}_{3} \mathrm{~N}_{4}$ form. Therefore, both twoand three-dimensional systems have shown an endothermic formation process $\left(\Delta H_{f, 0}>0\right)$ which will be the most predominant contribution to the free energy of formation of the $\mathrm{C}_{3} \mathrm{~N}_{4}$ phases. However, this general instability should not be very large to preclude the synthesis of $\mathrm{C}_{3} \mathrm{~N}_{4}$ systems since metastable carbon-based molecules such as acetylene (226 $\mathrm{kJ} / \mathrm{mol}$ ) are known. ${ }^{68}$ As already pointed by Badding in Ref. 63 , carbon nitrides with $\mathrm{C}_{3} \mathrm{~N}_{4}$ stoichiometry could, in principle, likely be synthesized in high-pressure and hightemperature conditions with the actual techniques.

b. $C_{11} N_{4}$. The possibility to find a $\mathrm{C}_{11} \mathrm{~N}_{4}$ form, such as, for example, the graphiticlike phase, thermodynamically favorite with respect to the carbon poor systems, can be first inspected by plotting the cohesive energies against the various stoichiometries. From Fig. 7 it appears evident that a mixture of carbon and gr- $\mathrm{C}_{3} \mathrm{~N}_{4}$ is more stable than $\mathrm{gr}-\mathrm{C}_{11} \mathrm{~N}_{4}$. More precisely, the $\Delta H_{f, 0}$ computed for the formation reaction given in Eq. (10) has been estimated with the US-PP method to be positive and sensibly larger than that of the of $\mathrm{C}_{3} \mathrm{~N}_{4}$ (see Table VII and Fig. 8). From the calculation of the various formation enthalpies it can be suggested that a layered form of $\mathrm{C}_{11} \mathrm{~N}_{4}$ could only be favored over the formation of a three-dimensional $\mathrm{C}_{3} \mathrm{~N}_{4}$ phase (e.g., psc- $\mathrm{C}_{3} \mathrm{~N}_{4}$ ). In particular, when comparing the two graphiticlike forms with each other, a difference of $62.3 \mathrm{~kJ} / \mathrm{mol}$ in the $\Delta H_{f, 0}$ has been

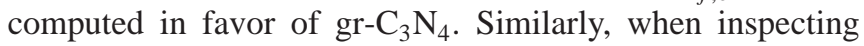

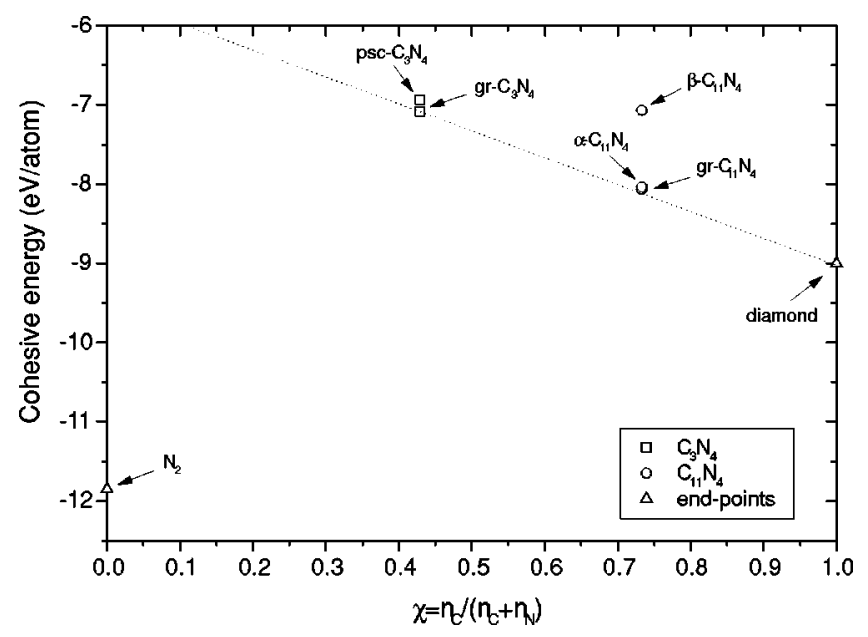

FIG. 7. The cohesive energy (eV/atom) is plotted versus the stoichiometry $\chi=n_{c} /\left(n_{c}+n_{n}\right)$. The values associated with $n_{c}$ and $n_{n}$ represent the number of $\mathrm{C}$ and $\mathrm{N}$ atoms in the unit cell. As end points we have used molecular $\mathrm{N}_{2}$ and diamond. Notice the position of the $\mathrm{gr}-\mathrm{C}_{11} \mathrm{~N}_{4}$ above the dot line connecting diamond and gr- $\mathrm{C}_{3} \mathrm{~N}_{4}$. 


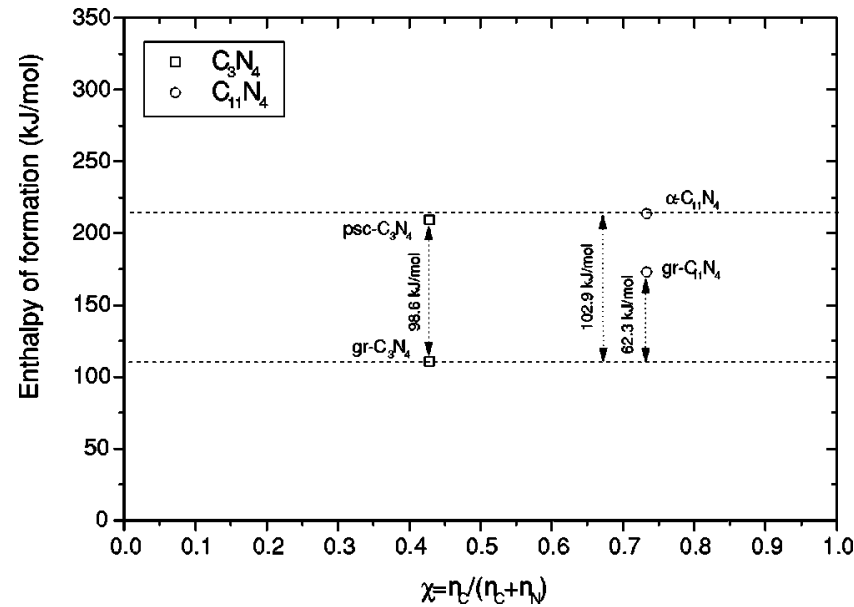

FIG. 8. Enthalpy of formation $\left(\Delta H_{f, 0}\right.$ in $\left.\mathrm{kJ} / \mathrm{mol}\right)$ against stoichiometry.

the possibility to synthesize carbon nitrides with an extended $s p^{3}$-bonded network, the same trend in the enthalpy of formation has been highlighted. Calculations suggest an enthalpy of formation slightly favored $(4.3 \mathrm{~kJ} / \mathrm{mol})$ for the $\mathrm{C}_{3} \mathrm{~N}_{4}$ form. A straightforward explanation to this general tendency can be found in the energy balance of Eq. (10). From this equation it appears quite obvious that the energy required for the breaking of the strong C-C bonds of the carbon-rich regime (i.e., diamond or graphite) can be hardly compensated with the cohesive energy of the $\mathrm{C}_{11} \mathrm{~N}_{4}$ stoichiometry $\left(\sim 1.0 \mathrm{eV}\right.$ /atom larger than $\mathrm{C}_{3} \mathrm{~N}_{4}$ with the US-PP/ LDA scheme). Therefore, from a pure thermodynamic point of view the $\mathrm{C}_{3} \mathrm{~N}_{4}$ composition should be generally favored over the synthesis of the isoelectronic $\mathrm{C}_{11} \mathrm{~N}_{4}$.

c. Conclusions. At first sight, the above result seems to be in contrast with the experience accumulated in depositing carbon-based compounds with magnetron sputtering, which is one of the most dominating processes for depositing hard materials. However, it is important to specify that such a conclusion has been drawn by comparing results coming from a limited number of model systems, which have been assumed to be representative for the layered and the threedimensional $\mathrm{CN}_{x}$ forms. Therefore, it cannot a priori be excluded that a further spanning of the space of the crystal structures might lead to the discovery of other stable phases with a very different trend in the enthalpy of formation. It is also worth noting that the experimental results actually available in the literature are mostly relevant to amorphous samples with a graphiticlike/fullerenelike form for which the analogy with the presented crystalline models is somehow arbitrary. Furthermore, a detailed kinetic study should be introduced for a complete understanding of the problem. It is in fact crucial to note that the synthesis of carbon nitrides is usually performed at high temperatures where kinetic factors can play an important and predominating role. The stability

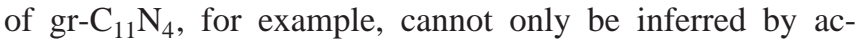
counting for its thermodynamic stability but also needs a deep kinetic investigation to understand its real phase stability. As a matter of fact, $\mathrm{C}_{11} \mathrm{~N}_{4}$ compounds could be thermodynamically unstable but at the same time kinetically more
TABLE VIII. Theoretical values of the elastic constants $\left(c_{i j}\right.$ in $\mathrm{GPa}$ ), isotropic shear modulus ( $G$ in $\mathrm{GPa}$ ), bulk modulus ( $B$ in $\mathrm{GPa})$, its pressure derivative $\left(B^{\prime}\right)$, atomic volume $\left(V_{o}\right.$ in $\AA^{3}$ /atom), cohesive energy ( $E_{o}$ in $\mathrm{eV} /$ atom), and atomic densities ( $\rho$ in $\mathrm{g} / \mathrm{cm}^{3}$ ) of psc- $\mathrm{C}_{3} \mathrm{~N}_{4}$ and $\alpha-, \beta-\mathrm{C}_{11} \mathrm{~N}_{4}$. The $E_{o}$ values refer to the cohesive energies calculated with respect to the spherical nonspin-polarized atoms, i.e., without applying the atomic spinpolarization corrections. Values in brackets refer to the work of Liu and Wentzcovitch (Ref. 55).

\begin{tabular}{lccc}
\hline \hline$c_{i j}$ & $\mathrm{psc} \mathrm{C}_{3} \mathrm{~N}_{4}$ & $\alpha-\mathrm{C}_{11} \mathrm{~N}_{4}$ & $\beta-\mathrm{C}_{11} \mathrm{~N}_{4}$ \\
\hline$c_{11}$ & $842.85(840)$ & 959.44 & 728.52 \\
$c_{12}$ & $217.38(213)$ & 151.72 & 206.93 \\
$c_{13}$ & & 356.28 & 205.59 \\
$c_{22}$ & & & 727.21 \\
$c_{23}$ & & & 209.07 \\
$c_{33}$ & & 1274.42 & 616.21 \\
$c_{44}$ & $454.61(452)$ & 617.83 & 252.84 \\
$c_{55}$ & & & 347.96 \\
$c_{66}$ & & 588.95 & 235.45 \\
$G$ & $397.86(397)$ & 520.19 & 263.94 \\
$B$ & $425.87(425)$ & 460.59 & 367.18 \\
$B^{\prime}$ & 3.80 & 5.27 & 3.61 \\
$V_{o}$ & 5.66 & 5.58 & 5.91 \\
$E_{o}$ & -9.1162 & -9.6610 & -8.7033 \\
$\rho$ & 3.86 & 3.71 & 3.52 \\
\hline \hline
\end{tabular}

favorable than $\mathrm{C}_{3} \mathrm{~N}_{4}$ due to the presence of a larger number of strong $\mathrm{C}-\mathrm{C}$ bonds.

\section{HARDNESS: ANALYSIS OF THE RESULTS AND DISCUSSION}

In the following section we comment the results achieved with the US-PP method (Table VIII) by straining the solids in a volume- and shape-changing way. The calculated bulk modulus for $\alpha-\mathrm{C}_{11} \mathrm{~N}_{4}$ was found to be $460.59 \mathrm{GPa}$. This value is larger than the estimated moduli for $\mathrm{psc}-\mathrm{C}_{3} \mathrm{~N}_{4}$ $(425.87 \mathrm{GPa})$, cubic boron nitride $(396.60 \mathrm{GPa})$ and close to those of cubic (463.68 GPa) and hexagonal (456.03 GPa) diamond. ${ }^{67}$ On the contrary, for the $\beta$ phase, a much lower $B$ $(367.18 \mathrm{GPa})$ has been calculated. However, its magnitude approaches that of cubic boron nitride. As already discussed in the above section, the difference in the bulk moduli between $\alpha$ and $\beta$ can roughly be related to the lower stability of $\beta$. Adjusting the variation of the energy versus the unitcell volume for the layered $\mathrm{C}_{3} \mathrm{~N}_{4}$ and $\mathrm{C}_{11} \mathrm{~N}_{4}$ phases we found the following $B$ numbers: $47.3 \mathrm{GPa}$ and $46.4 \mathrm{GPa}$. These moduli are quite close to each other indicating how the hardness of layered carbon nitrides remains mostly invariant with respect to a significant lowering of the nitrogen concentration.

The systematic investigation of the lattice stability was originally done by Born and Huang, ${ }^{74,75}$ who showed that by expanding the internal crystal energy as a power series in the strain and by imposing the convexity of the energy, it is possible to obtain stability criteria in terms of a set of con- 
ditions on the elastic constants. The requirement of mechanical stability in a cubic crystal leads to the following restrictions on the three elastic constants: ${ }^{76}$

$$
\left(c_{11}-c_{12}\right)>0, \quad c_{11}>0, \quad c_{44}>0, \quad\left(c_{11}+2 c_{12}\right)>0 .
$$

For a tetragonal crystal, which has six independent elastic constants, these conditions are as follows: ${ }^{76}$

$$
\begin{gathered}
\left(c_{11}-c_{12}\right)>0, \quad\left(c_{11}+c_{33}-2 c_{13}\right)>0, \\
c_{11}>0, \quad c_{33}>0, \quad c_{44}>0, \quad c_{66}>0, \\
\left(2 c_{11}+c_{33}+2 c_{12}+4 c_{13}\right)>0 .
\end{gathered}
$$

Finally, for orthorhombic crystals with nine elastic constants, the mechanical stability leads to the following restrictions: ${ }^{76}$

$$
\begin{gathered}
\left(c_{11}+c_{22}-2 c_{12}\right)>0, \quad\left(c_{11}+c_{33}-2 c_{13}\right)>0 \\
\left(c_{22}+c_{33}-2 c_{23}\right)>0, \\
c_{11}>0, \quad c_{22}>0, \quad c_{33}>0, \quad c_{44}>0, \quad c_{55}>0, \quad c_{66}>0, \\
\left(c_{11}+c_{22}+c_{33}+2 c_{12}+2 c_{13}+2 c_{23}\right)>0 .
\end{gathered}
$$

The complete set of zero-pressure elastic constants are shown in Table VIII together with the related isotropic shear moduli. The first thing to note is that the whole set of $c_{i j}$ satisfies all the above conditions, indicating a certain mechanical stability for the $\alpha$ and $\beta$ phases. Therefore, even though they are not the most energetically favored structures for the $\mathrm{C}_{11} \mathrm{~N}_{4}$ stoichiometry, they could be at least metastable materials. The calculated shear moduli validate the same hardness trend as found with the estimated bulk moduli. The isotropic $G$ value for the $\alpha$ phase is about $122 \mathrm{GPa}$ higher than that of psc- $\mathrm{C}_{3} \mathrm{~N}_{4}$, indicating a clear hardening of the $\mathrm{C}_{11} \mathrm{~N}_{4}$ stoichiometry over the $\mathrm{C}_{3} \mathrm{~N}_{4}$ analog. As expected, the calculated moduli was found for the $\beta$ phase well below the value of the $\alpha$ structure, thus confirming the destabilizing effect of the carbon holes with dangling bonds.

It is certain that the introduction of arbitrary deformations of the unit cell followed by the calculation of the total energy, which is many orders of magnitude larger than elastic energy, tends to decrease the accuracy of the calculated moduli. Nonetheless, the extrapolated isotropic shear moduli for diamond and cubic boron nitride have been recently shown to be in good agreement with the experimental results. ${ }^{67}$ Consequently, the large and positive $c_{i j}$ values found for the three-dimensional $\alpha-\mathrm{C}_{11} \mathrm{~N}_{4}$ model system can be taken as a reference in accounting for its large hardness. It is worth noting that by augmenting the number of $s p^{3}$ carbon tetrahedra, the hardness of the material gets closer to that of diamond $\left[G_{\text {exp }}=535 \mathrm{GPa}\right.$ and $B_{\text {exp }}=443 \mathrm{GPa} ;{ }^{44} G_{\text {cal }}$ $=558.5 \mathrm{GPa}$ and $B_{c a l}=463.7 \mathrm{GPa}$ (Ref. 67)]. As a matter of fact the resistance to deformation is improved in the $\alpha$ phase by the presence of a large number of $s p^{3}$ carbons, which have difficult access to higher electronic states, namely, $d$ states. From this picture, the process of rehybrid-

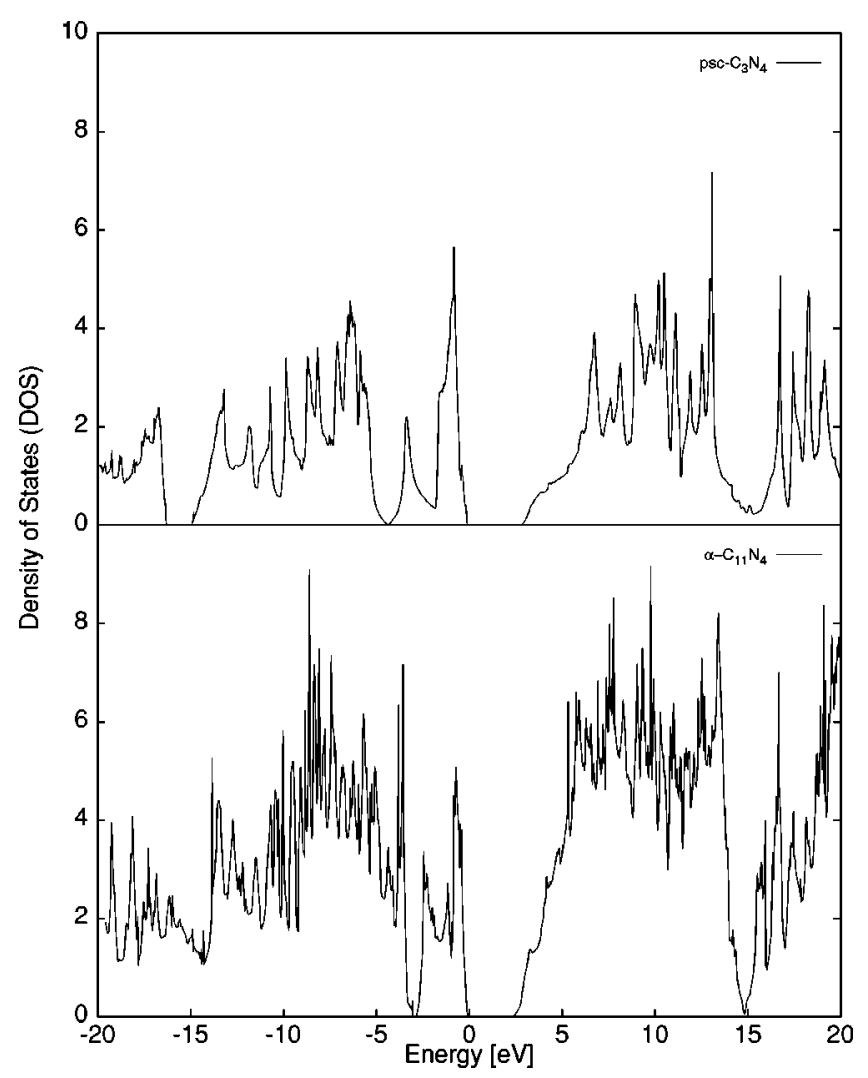

FIG. 9. The calculated total DOS for psc- $\mathrm{C}_{3} N_{4}$ and $\alpha-\mathrm{C}_{11} N_{4}$ (FP-LAPW).

ization, which takes place after deformation of the solid, has results, unfavorable thus leading to less compliant bonds. It is because of this characteristic that diamond will probably remain the hardest known material with high elastic-constant values and a large shear modulus. ${ }^{44,77}$

\section{ELECTRONIC STRUCTURE}

\section{A. Density of states of psc- $\mathrm{C}_{3} \mathrm{~N}_{4}$}

The calculated electronic density of states (DOS) of psc- $\mathrm{C}_{3} \mathrm{~N}_{4}$ (Fig. 9) at the equilibrium structure shows a band gap $\mathrm{E}_{g}$ of $2.86 \mathrm{eV}$ with the use of LDA approximation. From the partial components of the DOS (not shown here), it is found that the lower part of the valence band (VB) consists mainly of $2 s$ orbitals from nitrogen and carbon atoms, whereas the middle portion $(-15 \mathrm{eV} \leqslant E \leqslant-5 \mathrm{eV})$ is dominated by the mixing of the $\mathrm{C}$ and $\mathrm{N} 2 p$-orbitals. The very sharp VB edge indicates the presence of highly localized $\mathrm{N}$ states with $2 p$ character. These states can be attributed to the nonbonding electrons belonging the so-called "nitrogen hole." Finally, the portion of the conduction band (CB) in between 5 and $15 \mathrm{eV}$ is mostly dominated by the states of carbon and nitrogen $2 p$.

\section{B. Density of states of $\alpha$ - and $\beta-C_{11} \mathrm{~N}_{4}$}

The total DOS for the $\alpha$ phase is illustrated in Fig. 9. This structure shows a band gap of $2.40 \mathrm{eV}$, whereas for the $\beta$ phase no $E_{g}$ was found. The total DOS relative to $\alpha$ displays 
nearly the same $2 p$-state mixing as in the isoelectronic psc- $\mathrm{C}_{3} \mathrm{~N}_{4}$. The peak located at the top of the VB still consists of nitrogen states with $2 p$ character. Both the $\mathrm{VB}$ and $\mathrm{CB}$ are sharper and indicative of larger electron density. As already mentioned, the $\beta$ phase does not show any band gap. This is mainly due to the presence of carbon states located just above the Fermi energy $E_{F}$. Their existence is assigned to the highly distorted tetrahedral geometries of the atoms constituting the carbon hole.

\section{Calculation of energy loss near edge structure}

For light elements like carbon, boron, and nitrogen, electron-energy-loss spectroscopy is a useful technique because of its ability to differentiate the types of bonding in a polymorphic material. The characteristic fine structure in the first few $\mathrm{eV}$ beyond the beginning of the core-loss ionization edges [energy loss near edge structure (ELNES)] supplies the so-called coordination fingerprints, which can be used to distinguish different phases in complex systems. Since in our case of theoretically predicted $\mathrm{CN}_{x}$ phases no such reference spectra exist, it becomes worth having a theoretical approach to simulate the ELNES. The calculation of the energy loss near edge structures has been performed with the WIEN97 code according to the formalism of Nelhiebel et al. ${ }^{78} \mathrm{Here}$, we present spectra due to the carbon and nitrogen $K$-shell excitation $(n=1, l=0)$ of various $\mathrm{CN}_{x}$ compounds. Parameter settings were used to simulate polycrystalline samples by averaging over all possible incident-beam directions (integral over $4 \pi$ ). Nonetheless, the neglected anisotropy effects, which are mostly important for layered structures, should only change the intensity of the peaks but not their positions. The energy of the incident electrons was fixed to $200 \mathrm{KeV}$ and the energy loss of the first edge to 285 and 400 $\mathrm{eV}$ for carbon and nitrogen, respectively.

In order to probe our calculational method, diamond and graphite have also been investigated. Their relative C $K$ ELNES spectra are depicted in Fig. 10 and the position of the most prominent peaks (labeled I-IV) are listed in Table IX. Peak I in the C $K$ edge of graphite corresponds to the electronic transitions $1 s \rightarrow \pi^{*}$. This feature usually identifies $s p^{2}$-hybridized materials and consequently it does not appear in the diamond spectra. The peaks II-V are related to $1 \mathrm{~s}$ $\rightarrow \sigma^{*}$ transitions. A reasonable correspondence between our calculations and the experimental results is found in Table IX. Moreover, our relative peak positions match better with the experimental finding than the multiple-scattering (MS) -approach calculations. ${ }^{79}$

The calculated plain and broadened spectra for different $\mathrm{CN}_{x}$ materials are shown in Figs. 11 and 12 for the $\mathrm{C}$ and $\mathrm{N}$ $K$ edges, respectively. The spectra for gr- $\mathrm{C}_{3} \mathrm{~N}_{4}$ and gr- $\mathrm{C}_{11} \mathrm{~N}_{4}$ reveal mainly graphitic features (Fig. 11), whereas the threedimensional psc- $\mathrm{C}_{3} \mathrm{~N}_{4}$ and $\alpha-\mathrm{C}_{11} \mathrm{~N}_{4}$ exhibit a closer similitude to the diamond spectra. However, despite this general similarity, the shape and the number of $\sigma^{*}$ peaks relative to the $\mathrm{C}_{11} \mathrm{~N}_{4}$ spectra differ quite evidently from those calculated for the $\mathrm{C}_{3} \mathrm{~N}_{4}$ stoichiometry. Especially in the region between 5 and $15 \mathrm{eV}$ (in both edges) a different characteristic fingerprint can be assigned to each of the studied systems, thus

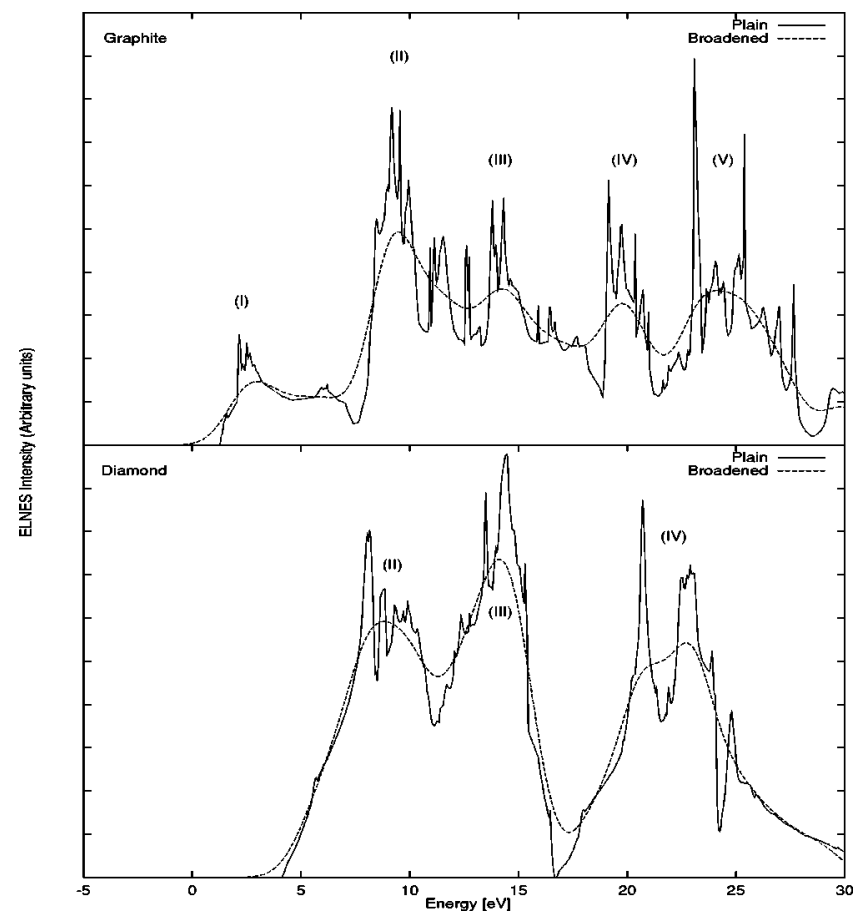

FIG. 10. Theoretical C $K$ ELNES of diamond and graphite (FPLAPW).

opening the possibility to identify these model phases in thin-film samples via the EELS technique.

The particular sharp $\pi^{*}$ peak found at $\sim 0 \mathrm{eV}$ in the $\mathrm{N}$ edge spectra of gr- $\mathrm{C}_{11} \mathrm{~N}_{4}$ (plain line of Fig. 12) indicates the presence of a pronounced $s p^{2}$ bonding character. The main contribution to this feature is due to the $\mathrm{N}_{2}$ and $\mathrm{N}_{3}$ atoms constituting the 12-center carbon-nitrogen rings.

\section{CONCLUDING REMARKS}

The present investigation reports the study of the stability and hardness of two model carbon nitride stoichiometries: $\mathrm{C}_{x} \mathrm{~N}_{4}$, where $x=3$ and 11. In particular, it has been carried out for the theoretical equilibrium structural parameters and cohesive energies of novel $\mathrm{C}_{11} \mathrm{~N}_{4}$ phases. We have also shown how the introduction of an extended carbon system, which can be of graphiticlike or diamondlike type, can represent an important way to increase the cohesive energy in

TABLE IX. Positions of peaks I-V in the spectra in Fig. 10. All positions are scaled with respect to the main $\sigma^{*}$ peak II. Values are in units of $\mathrm{eV}$.

\begin{tabular}{|c|c|c|c|c|c|c|c|}
\hline Phase & Edge & & I & II & III & IV & V \\
\hline \multirow[t]{3}{*}{ Diamond } & C $K$ & this work & & 0 & 5.3 & 12.9 & \\
\hline & & MS approach ${ }^{a}$ & & 0 & 4.4 & 12.0 & \\
\hline & & expt. $^{\mathrm{a}}$ & & 0 & 5.5 & 12.9 & \\
\hline \multirow[t]{3}{*}{ Graphite } & C $K$ & this work & -6.4 & 0 & 4.6 & 10.0 & 14.3 \\
\hline & & MS approach ${ }^{a}$ & -4.9 & 0 & 2.5 & 6.6 & 10.3 \\
\hline & & expt. $^{\mathrm{a}}$ & -6.8 & 0 & 4.4 & 11.2 & 14.7 \\
\hline
\end{tabular}

${ }^{\mathrm{a}}$ As compiled in Ref. 79. 


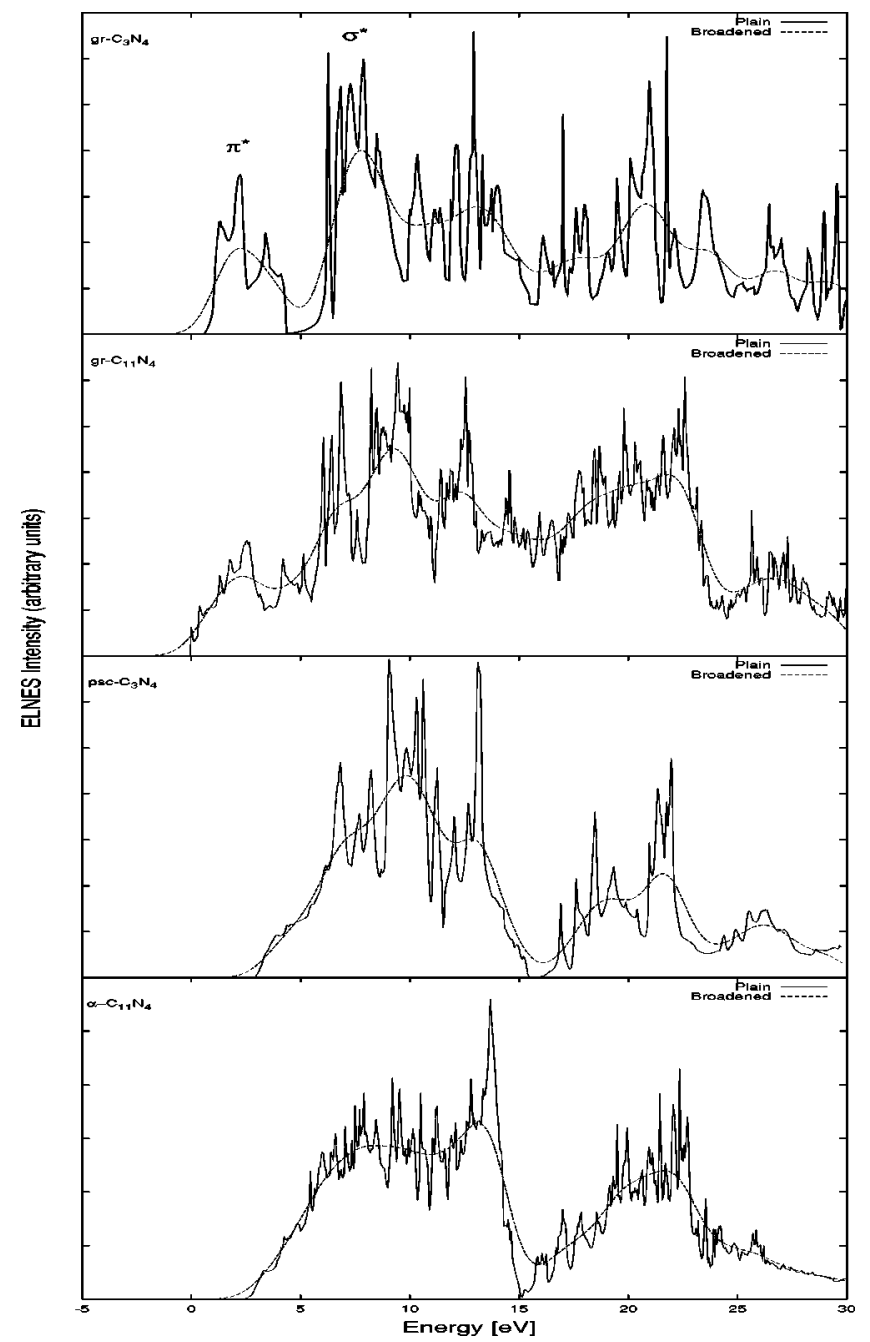

FIG. 11. Theoretical C $K$ ELNES of various $\mathrm{CN}_{X}$ phases (FPLAPW). The spectra for the inequivalent atoms positions have been calculated separately and weighted in the present figure.

carbon nitrides. However, calculations of $\Delta H_{f, 0}$ have suggested that despite the large increment of the cohesive energy, the layered $\mathrm{C}_{3} \mathrm{~N}_{4}$ system will remain thermodynamically preferable over the analogous $\mathrm{C}_{11} \mathrm{~N}_{4}$ composition. In contrast to the latest experimental finding, our work has shown that the synthesis of $\mathrm{CN}_{x}$ materials with higher carbon content should generally be less feasible than the wellknown $\mathrm{C}_{3} \mathrm{~N}_{4}$ stoichiometry.

However, for a complete understanding of the stability problem it is also very important to consider, beside the above thermodynamic factors, the various kinetic aspects that could play a dominant role in predicting the products of high-temperature reactions. As a matter of fact, starting from a simple chemical approach it can be imagined that the introduction of a large number of $\mathrm{C}-\mathrm{C}$ connections (i.e., strong bonds), such as, for instance, in the $\mathrm{C}_{11} \mathrm{~N}_{4}$ phases, could likely be responsible for an increased kinetic stability with respect to all the other substances showing only weaker C-N bonds (i.e., $\mathrm{C}_{3} \mathrm{~N}_{4}$ ). Certainly, this remains at the moment only an important hypothesis, which could in part explain the

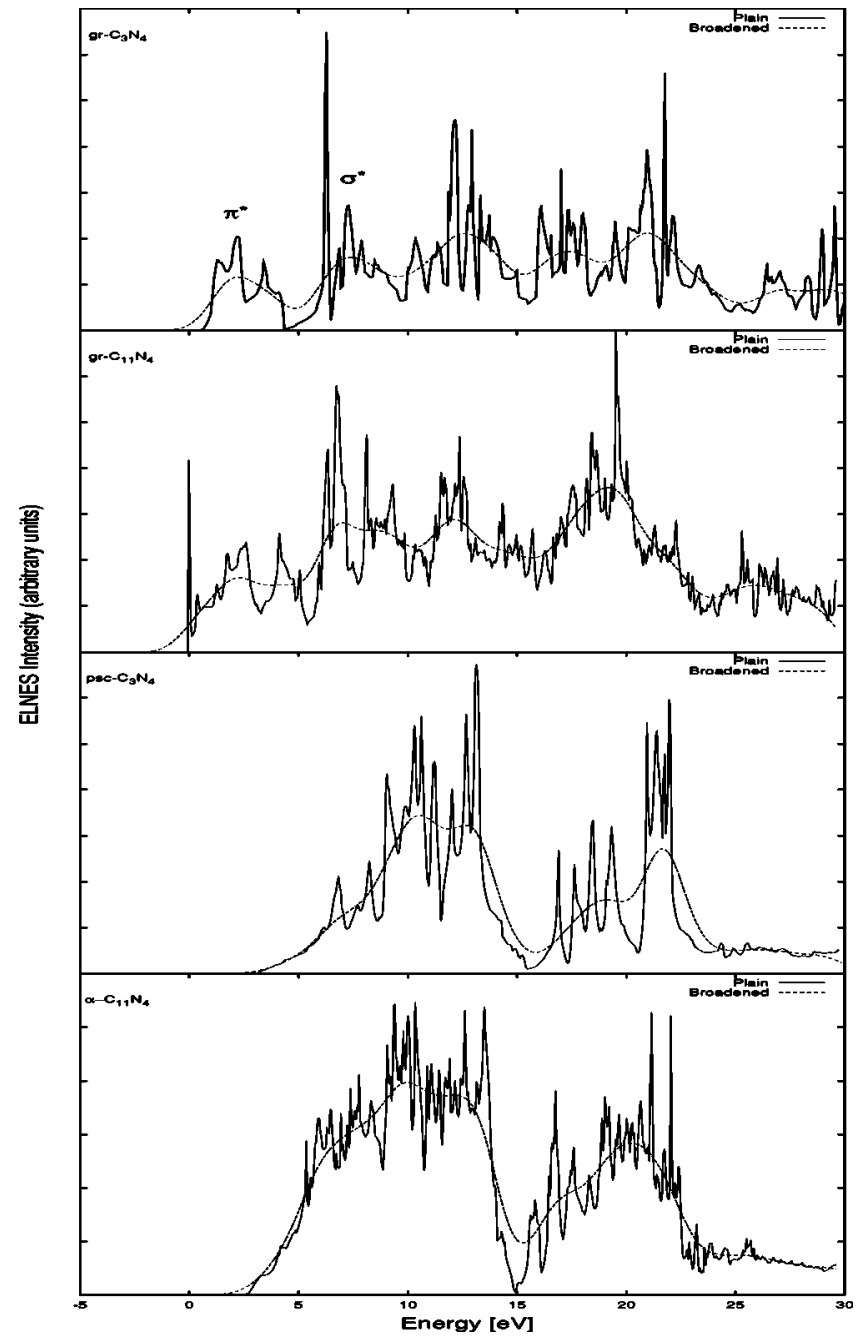

FIG. 12. Theoretical $\mathrm{N} K$ ELNES of various $\mathrm{CN}_{X}$ phases (FPLAPW). As in Fig. 11 inequivalent atoms have been calculated separately and weighted in the present spectra.

recent experimental finding. However, more efforts are needed in this direction in order to get a better understanding of the $\mathrm{CN}_{x}$ compounds.

Furthermore, the possibility to have a larger increment in the stability must also be searched in fullerenelike phases. In view of the latest experimental outcomes, nanotubes and nanofibers should also be considered as important forms for carbon nitrides. Unfortunately, due to the high cost of computational time needed for such an investigation we reserve this study for a possible future project.

A large part of this work has also been directed to the calculation of the independent, nonzero elastic constants from first principles. The analysis of the complete set of elastic moduli for the $\alpha$ phase shows how the $\mathrm{C}_{11} \mathrm{~N}_{4}$ stoichiometry can lead to the formation of hard and elastic materials. More generally, the increasing of the carbon concentration leads to a significant improvement in the hardness of carbon nitrides, provided that the same isoelectronic structure is kept in the model system. Furthermore, we have analyzed the density of states in order to gain insight into the 
chemical bonding of phases with different stoichiometries. Finally, the characteristic ELNES coordination fingerprints have been reported for various $\mathrm{CN}_{x}$ phases. The proposed spectra may be used as a precious tool for the characterization and identification of novel carbon nitrides phases in polymorphic samples.

\section{ACKNOWLEDGMENTS}

This work was financially supported by the Training and Mobility of Researchers (TMR) Network (FMRX-CT970103).
*Corresponding author. FAX +33 (0) 5568427 61. Email address: mattesin@icmcb.u-bordeaux.fr

${ }^{1}$ S. Iijima, Nature (London) 354, 56 (1991).

${ }^{2}$ S. L. Sung, S. H. Tsai, C. H. Tseng, F. K. Chiang, X. W. Liu, and H. C. Shih, Appl. Phys. Lett. 74, 197 (1999).

${ }^{3}$ K. Suenaga, M. P. Johansson, N. Hellgren, E. Broitman, L. R. Wallenberg, C. Colliex, J-E. Sundgren, and L. Hultman, J. Vac. Sci. Technol. B 300, 695 (1999).

${ }^{4}$ M. Terrones, P. Redlich, N. Grobert, S. Trasobares, W-K. Hsu, H. Terrones, Y-Q. Zhu, J. P. Hare, C. L. Reeves, A. K. Cheetham, M. Rühle, H. W. Kroto, and D. R. M. Walton, Adv. Mater. 11, 655 (1999).

${ }^{5}$ A. G. Rinzler, J.H. Hafner, P. Nikolaev, L. Lou, S. G. Kim, D. Tománek, P. Nordlander, D. T. Colbert, and R. E. Smalley, Science 268, 1550 (1995).

${ }^{6}$ W. A. de Heer, A. Châtelain, and D. Ugarte, Science 270, 1179 (1995).

${ }^{7}$ W. A. de Heer, J-M. Bonard, K. Fauth, A. Châtelain, L. Forró, and D. Ugarte, Adv. Mater. 9, 87 (1997).

${ }^{8}$ Yu. V. Gulyaev, L. A. Chemozatonskii, Z. Ja. Kosakovskaja, N. I. Sinitsyn, G. V. Torgashov, and Yu. F. Zakharchenko, J. Vac. Sci. Technol. B 13, 435 (1995).

${ }^{9}$ E. Broitman, W. Macdonald, N. Hellgren, G. Radnóczi, Zs. Czigány, A. Wennerberg, M. Jacobsson, and L. Hultman, Diamond Relat. Mater. 9, 1984 (2000).

${ }^{10}$ S. Muhl and J. M. Mendéz, Diamond Relat. Mater. 8, 1809 (1999).

${ }^{11}$ A. Y. Liu and M. L. Cohen, Science 245, 841 (1989).

${ }^{12}$ J. J. Cuomo, P. A. Leary, D. Yu, W. Reuter, and M. Frisch, J. Vac. Sci. Technol. 16, 299 (1979).

${ }^{13}$ M. Iwaki, K. Takahashi, and A. Sekiguchi, J. Mater. Res. 5, 2562 (1990).

${ }^{14}$ C. J. Torng, J. M. Siversten, J. H. Judy, and C. Chang, J. Mater. Res. 5, 2490 (1990).

${ }^{15}$ H-X. Han and B. J. Feldman, Solid State Commun. 65, 921 (1988).

${ }^{16}$ J. D. F. Chubaci, T. Sakai, T. Yamamoto, K. Agata, A. Ebe, and F. Fujimoto, Phys. Rev. B 80/81, 463 (1993).

${ }^{17}$ D. Li, Y. Chung, M. Wong, and W. D. Sproul, J. Appl. Phys. 74, 219 (1993).

${ }^{18}$ L. Maya, D. R. Cole, and E. W. Hagaman, J. Am. Ceram. Soc. 74, 1686 (1991).

${ }^{19}$ M. Ricci, M. Trinquecoste, F. Auguste, R. Canet, P. Delhaes, C. Guimon, G. Pfister-Guillouzo, B. Nysten, and J. P. Issi, J. Mater. Res. 8, 480 (1993).

${ }^{20}$ F. Fujimoto and K. Ogata, Jpn. J. Appl. Phys., Part 1 32, 420 (1993).

${ }^{21}$ C. Niu, Y. Z. Lu, and C. M. Lieber, Science 261, 334 (1993).

${ }^{22}$ N. Hellgren, M. P. Johansson, E. Broitman, L. Hultman, and J-E. Sundgren, Phys. Rev. B 59, 5162 (1999).
${ }^{23}$ N. Hellgren, Ph.D. thesis, Linköping University, Sweden, 1999.

${ }^{24}$ W. T. Zheng, H. Sjöström, I. Ivanov, K. Z. Xing, E. Broitman, W. R. Salaneck, and J-E. Sundgren, J. Vac. Sci. Technol. A 14, 2696 (1996).

${ }^{25}$ D. C. Nesting and J. V. Badding, Chem. Mater. 8, 1535 (1996).

${ }^{26}$ H. Sjöstrom, L. Hultman, J-E. Sundgren, S. V. Hainsworth, T. F. Page, and G. S. A. M. Theunissen, J. Vac. Sci. Technol. A 14, 56 (1996).

${ }^{27}$ D. A. Zhogolev, O. P. Bugaets, and I. A. Marushko, Zh. Strukt. Khim. 22, 46 (1981).

${ }^{28}$ T. H. Hall, Science 148, 1331 (1965).

${ }^{29}$ T. H. Hall and L. A. Compton, Inorg. Chem. 4, 1213 (1965).

${ }^{30}$ W. Kohn and L. J. Sham, Phys. Rev. 140, A1133 (1965); P. Hohenberg and W. Kohn, ibid. 136, B864 (1964).

${ }^{31}$ D. M. Ceperley and B. J. Alder, Phys. Rev. Lett. 45, 566 (1980).

${ }^{32}$ J. P. Perdew and A. Zunger, Phys. Rev. B 23, 5048 (1981).

${ }^{33}$ D. Vanderbilt, Phys. Rev. B 41, 7892 (1990).

${ }^{34}$ VASP (Vienna ab initio simulation program), developed at the Institut für Theoretische Physik of the Technische Universität Wien; G. Kresse and J. Hafner, Phys. Rev. B 47, 558 (1993); 49, 14251 (1994); G. Kresse and J. Furthmüller, Comput. Mater. Sci. 6, 15 (1996); Phys. Rev. B 54, 11169 (1996).

${ }^{35}$ P. E. Blöchl, O. Jepsen, and O. K. Andersen, Phys. Rev. B 49, 16223 (1994).

${ }^{36}$ H. J. Monkhorst and J. D. Pack, Phys. Rev. B 13, 5188 (1976).

${ }^{37}$ WIEn97, P. Blaha, K. Schwarz, and J. Luitz, wIEn97, A Full Potential Linearized Augmented Plane Wave Package for Calculating Crystal Properties (Karlheinz Schwarz, Techn. Universität, Wien, Austria, 1999), ISBN 3-9501031-0-4.

${ }^{38}$ J. P. Perdew and Y. Wang, Phys. Rev. B 45, 13244 (1992).

${ }^{39}$ M. Mattesini, S. F. Matar, A. Snis, J. Etourneau, and A. G. Mavromaras, J. Mater. Chem. 9, 3151 (1999).

${ }^{40}$ C. M. Sung and M. Sung, Mater. Chem. 43, 1 (1996).

${ }^{41}$ M. L. Cohen, Mater. Sci. Eng., A 105/106, 11 (1988).

${ }^{42}$ M. L. Cohen, Phys. Rev. B 32, 7988 (1985).

${ }^{43}$ M. L. Cohen, J. Hard Mater. 2, 13 (1991).

${ }^{44}$ D. M. Teter and R. J. Hemley, Science 271, 53 (1996).

${ }^{45}$ A. P. Gerk, J. Mater. Sci. 12, 735 (1977).

${ }^{46}$ D. M. Teter, MRS Bull. 23, 22 (1998).

${ }^{47}$ M. Hebbache, Solid State Commun. 113, 417 (2000).

${ }^{48}$ J. F. Nye, Physical Properties of Crystals: Their Representation by Tensors and Matrices (Oxford University Press, New York, 1985), ISBN 0198511655.

${ }^{49}$ P. Ravindran, J. Wills, and O. Eriksson, J. Appl. Phys. 84, 4891 (1998).

${ }^{50}$ M. J. Mehl, J. E. Osburn, D. A. Papaconstantopoulos, and B. M. Klein, Phys. Rev. B 41, 10311 (1990).

${ }^{51}$ M. J. Mehl, Phys. Rev. B 47, 2493 (1993).

${ }^{52}$ A. Reuss, Z. Angew. Math. Mech. 49, 9 (1929).

${ }^{53}$ F. Birch, J. Geophys. Res. 83, 1257 (1978). 
${ }^{54}$ J. Ortega and O. K. Sankey, Phys. Rev. B 51, 2624 (1995).

${ }^{55}$ A. Y. Liu and R. M. Wentzcovitch, Phys. Rev. B 50, 10362 (1994).

${ }^{56}$ M. Mattesini, S. F. Matar, and J. Etourneau, J. Mater. Chem. 10, 709 (2000).

${ }^{57} \mathrm{~A}$ graphiticlike $\mathrm{C}_{11} \mathrm{~N}_{4}$ system with a stacking sequence $A B A$ or $A B C$ would lead to a larger number of inequivalent atoms per unit cell. Furthermore, since the total energy interaction between layers is weak (as in the case of graphite) we have decided to compare the two graphiticlike stoichiometries by assuming a common $A A A$ packing of the layers.

${ }^{58}$ P. P. Lottici, G. Antonioli, and C. Razzetti, J. Phys. Chem. Solids 50, 967 (1989).

${ }^{59}$ A. Snis and S. F. Matar, Phys. Rev. B 60, 10855 (1999).

${ }^{60}$ A. Snis, S. F. Matar, O. Plashkevych, and H. Agren, J. Chem. Phys. 111, 9678 (1999).

${ }^{61}$ O. Plashkevych, A. Snis, L. Yang, H. Ågren, and S. F. Matar, Phys. Scr. 63, 70 (2001).

${ }^{62}$ T. Hughbanks and Y. Tian, Solid State Commun. 96, 321 (1995).

${ }^{63}$ J. V. Badding, Adv. Mater. 9, 877 (1997).

${ }^{64}$ A. Y. Liu, R. M. Wentzcovitch, and M. L. Cohen, Phys. Rev. B 39, 1760 (1989).

${ }^{65}$ H. Nozaki and S. Itoh, J. Phys. Chem. Solids 57, 41 (1996).

${ }^{66}$ Y. Tateyama, T. Ogitsu, K. Kusakabe, S. Tsuneyuki, and S. Itoh, Phys. Rev. B 55, 10161 (1997).

${ }^{67}$ M. Mattesini and S. F. Matar, Comput. Mater. Sci. 20, 107 (2001).

${ }^{68}$ D. A. Johnson, Some Thermodynamic Aspects of Inorganic Chemistry (Cambridge University Press, Cambridge, 1982).

${ }^{69}$ J. V. Badding and D. C. Nesting, Chem. Mater. 8, 535 (1996).

${ }^{70}$ S. F. Matar and M. Mattesini, C. R. Acad. Sci. Paris 4, 255 (2001).
${ }^{71}$ O. Gunnarsson and R. O. Jones, Phys. Rev. B 31, 7588 (1985).

${ }^{72}$ C. Mailhiot, L. H. Yang, and A. K. McMahan, Phys. Rev. B 46, 14419 (1992).

${ }^{73}$ S. Fahy, X. W. Wang, and S. G. Louie, Phys. Rev. B 42, 3503 (1990).

${ }^{74}$ M. Born, Proc. Cambridge Philos. Soc. 36, 160 (1940).

${ }^{75}$ M. Born and K. Huang, Dynamical Theory of Crystal Lattices (Clarendon, Oxford, 1956).

${ }^{76}$ D. C. Wallace, Thermodynamics of Crystals (Wiley, New York, 1972).

${ }^{77}$ W. A. Harrison, Electronic Structure and the Properties of Solids (Freeman, San Francisco, 1980).

${ }^{78}$ M. Nelhiebel, P. H. Louf, P. Schattschneider, P. Blaha, K. Schwarz, and B. Jouffrey, Phys. Rev. B 59, 12807 (1999).

${ }^{79}$ M. Wibbelt, H. Kohl, and Ph. Kohler-Redlich, Phys. Rev. B 59, 11739 (1999).

${ }^{80}$ D. C. Patton, D. V. Porezag, and M. R. Pederson, Phys. Rev. B 55, 7454 (1997).

${ }^{81}$ K. P. Huber and G. Herzberg, Molecular Structure and Molecular Spectra. IV. Constants of Diatomic Molecules (Van Nostrand Reinhold, New York, 1979).

${ }^{82}$ R. O. Jones and O. Gunnarsson, Rev. Mod. Phys. 61, 689 (1959).

${ }^{83}$ A. K. McMahan, Phys. Rev. B 30, 5835 (1984).

${ }^{84}$ J. Furthmüller, J. Hafner, and G. Kresse, Phys. Rev. B 50, 15606 (1994).

${ }^{85}$ M. T. Yin and M. L. Cohen, Phys. Rev. B 24, 6121 (1981).

${ }^{86}$ Value as compiled in Ref. 82.

${ }^{87}$ C. Kittel, Introduction to Solid State Physics, 6th ed. (Wiley, New York, 1986).

${ }^{88}$ G. S. Painter and F. Averill, Phys. Rev. B 26, 1781 (1982).

${ }^{89}$ In-Ho Lee and R. M. Martin, Phys. Rev. B 56, 7197 (1997). 